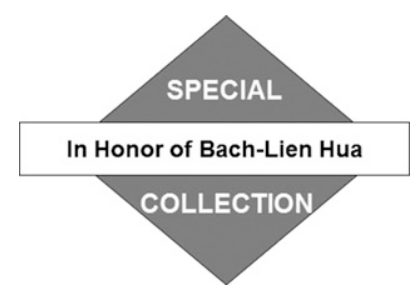

\title{
A Direct Determination of the World Ocean Barotropic Circulation
}

\author{
ALAIN COLIN DE VERDIÈRE \\ Laboratoire de Physique des Océans, Université de Bretagne Occidentale, Brest, France \\ Michel OlLitrault \\ Laboratoire de Physique des Océans, IFREMER, Centre de Brest, Plouzané, France
}

(Manuscript received 28 February 2015, in final form 30 October 2015)

\begin{abstract}
The time-mean Argo float displacements and the World Ocean Atlas 2009 temperature-salinity climatology are used to obtain the total, top to bottom, mass transports. Outside of an equatorial band, the total transports are the sum of the vertical integrals of geostrophic- and wind-driven Ekman currents. However, these transports are generally divergent, and to obtain a mass conserving circulation, a Poisson equation is solved for the streamfunction with Dirichlet boundary conditions at solid boundaries. The value of the streamfunction on islands is also part of the unknowns. This study presents and discusses an energetic circulation in three basins: the North Atlantic, the North Pacific, and the Southern Ocean. This global method leads to new estimations of the time-mean western Eulerian boundary current transports maxima of 97 Sverdrups (Sv; $1 \mathrm{~Sv} \equiv 10^{6} \mathrm{~m}^{3} \mathrm{~s}^{-1}$ ) at $60^{\circ} \mathrm{W}$ for the Gulf Stream, $84 \mathrm{~Sv}$ at $157^{\circ} \mathrm{E}$ for the Kuroshio, $80 \mathrm{~Sv}$ for the Agulhas Current between $32^{\circ}$ and $36^{\circ} \mathrm{S}$, and finally $175 \mathrm{~Sv}$ for the Antarctic Circumpolar Current at Drake Passage. Although the large-scale structure and boundary of the interior gyres is well predicted by the Sverdrup relation, the transports derived from the wind stress curl are lower than the observed transports in the interior by roughly a factor of 2, suggesting an important contribution of the bottom torques. With additional Argo displacement data, the errors caused by the presence of remaining transient terms at the $1000-\mathrm{db}$ reference level will continue to decrease, allowing this method to produce increasingly accurate results in the future.
\end{abstract}

\section{Introduction}

The present work provides a new direct method to obtain the total (or barotropic) transports. In this paper, barotropic transport means the integral of horizontal velocities from top to bottom (Welander 1959). The baroclinic velocity is then the difference between the actual velocity and the barotropic transport divided by the fluid depth (the vertical integral of the baroclinic velocity then vanishes). Another definition of barotropic, also widely used but different, is to multiply the velocity observed at a reference level by the oceanic depth (Fofonoff 1962). These two early papers indicate that determining the net mass transport has been a

Corresponding author address: A. Colin de Verdière, Laboratoire de Physique des Océans, Université de Bretagne Occidentale, CS 93837, 29238 Brest CEDEX, France.

E-mail: acolindv@univ-brest.fr long-standing objective in oceanography for at least three reasons: The first is practical because the meridional transfers of mass, heat, and freshwater can all be obtained through a barotropic-baroclinic modal decomposition of the velocity field (Bryan 1962; Hall and Bryden 1982). The second originates from Sverdrup's (1947) relation, which relates the meridional barotropic transport to the curl of the wind stress, which has become the building block of theories to predict the vertical structure of the circulation (Pedlosky 1996). World Ocean circulations based on this idea have been calculated by Godfrey (1989) and more recently by Risien and Chelton (2008) using QuikSCAT scatterometer data. However, both idealized numerical experiments (Holland 1972; Hughes and de Cuevas 2001) and reconstructions of the North Atlantic circulation from observations by Sarkisyan and Ivanov (1971), Mellor et al. (1982), Greatbatch et al. (1991), Bogden et al. (1993), and others have challenged the flat-bottom 
Sverdrup's theory and show that bottom torques can raise the barotropic response significantly above the Sverdrup value. The third is a link to the time-dependent motions; with kinetic energy dominated by the geostrophic eddies, turbulent cascades have a tendency to transfer kinetic energy to large-scale barotropic structures (Rhines 1977; Salmon 1980). The barotropic circulation can then be seen as the end product of these turbulent cascades. Its determination in eddy-rich regions, such as the western boundary inertial recirculation regions or the Antarctic Circumpolar Current (ACC), can become a useful benchmark for judging whether the nonlinear interactions are operating correctly in ocean eddy-resolving models.

The baroclinic velocities are obtained locally from the thermal wind equation. The determination of the barotropic circulation has proved more elusive, and the search has proceeded from several directions. The knowledge of absolute currents requires the determination of a level of reference, a level where the currents are directly measured, and this has turned out to be possible at key passages mostly along western boundaries using Eulerian mooring technology. $\mathrm{Nu}-$ merous comparisons of western boundary current transport with Sverdrup's predictions have been made. If no net flow occurs across a zonal section, the net interior Sverdrup flow must be returned by an equal and opposite western boundary transport, which can be directly compared to the local time-mean estimates. Often the presence of inertial recirculations makes such comparisons meaningless. In the Florida Straits (the entry of the western boundary layer), Schmitz et al. (1992) concluded that the Sverdrup transports compare well with observed transports once contributions from the South Atlantic are subtracted out. Farther downstream the western boundary current transports increase to values much larger than the Sverdrup transports. The eddyresolving quasigeostrophic studies of Holland (1978) showed readily that the large inertial recirculations were eddy driven.

The determination of barotropic transports in the interior of oceanic basins offers a better ground for comparisons with Sverdrup's theory, but this was prevented by the difficulty of obtaining direct measurements of the reference level on a large scale. Worthington (1976) and Reid (1994) presented total transport maps for the Atlantic where the geostrophic flow relative to the bottom was inferred from density, while the bottom flow was adjusted to be consistent with the tracers' distribution on isopycnal surfaces. In the view of the intuitive character for some choices of the bottom flow, alternative model developments appeared along several directions: (i) Inverse models introduced by Wunsch (1978) constrained the missing reference level velocities by imposing mass conservation along synoptic hydrographic sections, plus a condition of kinetic energy minimum at depth. North Atlantic inversions are found in Wunsch and Grant (1982), Olbers et al. (1985), Provost and Salmon (1986), and Paillet and Mercier (1997) (who also calculated a barotropic streamfunction), among many others. North Pacific inversions were carried out by Roemmich and McCallister (1989) and World Ocean inversions were carried out by Ganachaud and Wunsch (2000) using WOCE hydrographic data. (ii) Inverse models using a combination of hydrographic and velocity data (SOFAR floats) were carried out by Mercier et al. (1993). (iii) The beta spiral method of Stommel and Schott (1977) is based upon conservation of potential vorticity along isopycnal surfaces [see also a closely related study by Park and Guernier (2001)]. (iv) In the methods based on the depth-integrated barotropic vorticity equation by Mellor et al. (1982), and later Bogden et al. (1993), the barotropic streamfunction is obtained by integrating along potential vorticity contours the two forcings: the Ekman pumping and the baroclinic contribution to bottom pressure torque [the so-called JEBAR effect found by Sarkisyan and Ivanov (1971)]. (v) Quite a number of other studies used full blown OGCMs to spin up the barotropic circulation keeping the model temperature and salinity close to the observed time-mean temperature and salinity (Sarkisyan and Keonjiyan 1975; Holland and Hirschman 1972; Sarmiento and Bryan 1982; Ezer and Mellor 1994; Huck et al. 2008). (vi) Direct observations of the time-mean flow on a global scale started at the ocean surface with the tracking of surface drifters that allowed the reconstruction of an absolute surface mean dynamic topography (Niiler et al. 2003; Maximenko et al. 2009). The deep circulations have been obtained at the scale of oceanic basins with SOFAR, RAFOS, and ALACE floats in the wake of the WOCE experiment by Davis (2005) in the Pacific and Indian Ocean; Gille (2003) in the ACC; and Bower et al. (2002), Lavender et al. (2000), and Willis and Fu (2008) in the North Atlantic. The continuously increasing Argo float coverage now offers global perspectives as well, and reconstructions have been carried out by Katsumata and Yoshinari (2010) and Gray and Riser (2014) using Davis's (2005) objective analysis formulation. Ollitrault and Colin de Verdiere (2014, hereinafter OCV) proposed a new, dynamics-based method to filter out the divergent part of the velocity field. (vii) With the advent of gravimetric satellites allowing the determination of the geoid, the surface-mean dynamic topography can be obtained by difference with the time-mean altimetric 
surface, along with surface velocity from drifters and Argo floats (Rio et al. 2014). (viii) Assimilation models such as ECCO-GODAE are able to include all available time-dependent observations in a primitive equation model, the barotropic circulation being obtained through time averaging of the model variables (Wunsch and Heimbach 2007). Of course, these references are just a personal selection of a much larger ensemble of studies dedicated to the determination of the large-scale ocean circulation from observations.

The direct determination of the barotropic circulation first restricted to western boundary layers' sections can now be extended to the World Ocean interior with the growing Argo float displacements database. Since the temperature-salinity climatology is given on an Eulerian grid, the first task is to project the Lagrangian Argo float data on such an Eulerian grid, but a problem arises immediately because the horizontal divergence of the time-mean velocities is as large as the relative vorticity in some regions. Although the nominal "10-day-averaged" Lagrangian velocities are expected to be quasigeostrophic, the large divergence indicates that the time-mean Eulerian velocities are not, the large divergence being caused by the insufficient number of degrees of freedom in some regions. OCV have filtered out this spurious horizontal divergence through the inversion of the balance equation (Charney 1955), which recovers the geopotential from the vorticity (more precisely the curl of the vector $f \mathbf{u}$, with $f$ the Coriolis parameter). From the geopotential, geostrophic velocities are then obtained at $1000 \mathrm{db}$ with an unprecedented geographic coverage outside an equatorial band.

To obtain the barotropic circulation, the objective of the present paper, the new method uses this $1000-\mathrm{db}$ geopotential and hydrostatics to obtain the geopotential at all depths given the time-mean temperatures and salinities. The top to bottom integral of the absolute geostrophic and Ekman wind-driven currents gives directly the barotropic transports. However, two related difficulties need to be overcome: first, such barotropic transports are divergent, and second, they do not satisfy the condition of zero normal flow at solid boundaries. The divergence should in fact be no larger than evaporation-precipitation-riverine $(E-P-R)$ input that affects interbasin transports at an order of 1 Sverdrup $\left(\mathrm{Sv} ; 1 \mathrm{~Sv} \equiv 10^{6} \mathrm{~m}^{3} \mathrm{~s}^{-1}\right)$, for example, the net transport from the Pacific to the Atlantic through the Bering Straits (e.g., Wijffels et al. 1992; Woodgate et al. 2012). Neglecting this small divergence, the solution to both difficulties lies in the determination of a barotropic streamfunction with adequate boundary conditions. Forcing the transports to derive from a streamfunction ensures the nondivergence. A Poisson equation $\nabla^{2} \psi=\zeta$ then results with $\psi$ as the streamfunction and $\zeta$ as a given function of the observed barotropic transports (see section 2 below). The condition of no normal flow on solid boundaries is imposed by forcing the streamfunction to be constant there. In the North Atlantic or North Pacific cases, we set $\psi=0$ on all boundaries (neglecting the small exchange at Bering Strait). This straightforward procedure is valid for simply connected domains. In the Southern Hemisphere, however, a number of large islands stands out (the Antarctic continent, Australia, New Zealand, Crozet-Kerguelen Plateau, and Madagascar, to name the largest), and the values of $\psi$ on such islands become part of the unknowns. Following Kamenkovitch (1962), the observations of circulation around each island are used as additional constraints.

We emphasize that the baroclinic and barotropic parts of the large-scale circulation have a different nature. The baroclinic circulation is obtained from a purely local determination using the thermal wind, while the barotropic circulation is the solution of an elliptic problem of a global scale. It is the coverage of the Argo float displacements database and the (steadily increasing) number of observations in each $1^{\circ} \times 1^{\circ}$ square that allow this calculation. The present method is different from the one based on the vorticity equation pioneered by Sarkisyan and Ivanov (1971) and much developed by Mellor et al. (1982) and later by Bogden et al. (1993). In such vorticity-based methods, the barotropic flow is forced by the wind stress curl and by the vortex stretching caused by bottom vertical velocities. Here, besides hydrostatics and integral mass conservation, the sole additional assumption is geostrophy, so that this direct method retains Rossby number accuracy.

The method is described in section 2. Section 3 describes the connection between the present method and the vorticity theory. The new method is then applied to the North Atlantic with a discussion of the Sverdrup relation in section 4. The North Pacific and the Southern Hemisphere (for latitudes less than $10^{\circ} \mathrm{S}$ ) circulations are described in sections 5 and 6 , respectively. The total transports of all major currents and recirculation systems are discussed and it becomes a simple matter to compare this observed barotropic circulation with the Sverdrup relation in each basin.

\section{Methodology}

\section{a. The Poisson equation}

OCV have computed a World Ocean geopotential $\Phi\left(p_{R}\right)$ at a pressure $p_{R}$ around $1000 \mathrm{db}$ at $1^{\circ}$ spatial resolution from Argo float displacements of the ANDRO 
database. A description of the work done to obtain ANDRO is given by Ollitrault and Rannou (2013). Presently, the ANDRO dataset contains Argo float displacements before 1 January 2010, collected from the 10 following Data Assembly Centers (DAC): AOML, Coriolis, JMA, CSIRO, British Oceanographic Data Centre (BODC), Marine Environmental Data Service (MEDS), Indian National Centre for Ocean Information Services (INCOIS), Korean Ocean Research and Development Institute (KORDI), Korean Meteorological Administration (KMA), and the China Second Institute of Oceanography (CSIO). In this paper, we use only the 394035 displacements found in the $[950,1150]$ dbar layer and whose parking times may vary between 4 and 17 days. These displacements have been averaged in $1^{\circ} \times 1^{\circ}$ bins to produce a gridded field of Eulerian-mean horizontal velocities. These velocities are assumed geostrophic so that

$$
f \mathbf{k} \times \mathbf{u}\left(p_{R}\right)=-\nabla \Phi\left(p_{R}\right),
$$

with $\Phi\left(p_{R}\right)$ as the geopotential of the 1000-db surface, $f$ as the Coriolis parameter, $\nabla$ as the horizontal gradient at constant pressure, and $\mathbf{k}$ as the vertical unit vector. OCV have shown how to obtain $\Phi\left(p_{R}\right)$ from the knowledge of $\mathbf{u}\left(p_{R}\right)$ only. We now use the World Ocean Atlas 2009 (WOA 2009; Antonov et al. 2010; Locarnini et al. 2010) to obtain the in situ density from the temperaturesalinity distribution and combine with hydrostatics to obtain the geopotential at any pressure $p$ :

$$
\Phi(p)=\Phi\left(p_{R}\right)-\int_{p_{R}}^{p} d p / \rho,
$$

where $p_{R}=1000 \mathrm{db}$. Given $\Phi(p)$, the geostrophic relation (1) applied at any pressure $p$ gives the absolute geostrophic current at that pressure, noted $\mathbf{u}_{G}(p)$ for clarity in the following. To get the barotropic transport, one must add the wind-driven Ekman transport $\mathbf{U}_{E}$ given by

$$
\rho_{0} f \mathbf{k} \times \mathbf{U}_{E}=\tau,
$$

where the density $\rho$ has been approximated by $\rho_{0}=$ $1027 \mathrm{~kg} \mathrm{~m}^{-3}$ (the mean surface value), and $\tau$ is the wind stress. To compute the Ekman transports, we use Large and Yeager's (2004) wind stress climatology. The dynamics governing the geostrophic flow $\mathbf{u}_{G}$ also obeys

$$
f \mathbf{k} \times \rho \mathbf{u}_{G}=-\nabla p,
$$

where now the horizontal $\nabla$ operator is computed at constant $z$. Integrating (4) from the bottom $z=-H$ to the surface at $z=0$, and adding (3), yields the equation for the total mass transport:

$$
\begin{aligned}
f \mathbf{k} \times \mathbf{M} & =-\int_{-H}^{0} \nabla p d z+\tau \\
\mathbf{M} & =\int_{-H}^{0} \rho \mathbf{u}_{G} d z+\rho_{0} \mathbf{U}_{E} .
\end{aligned}
$$

It is a simple matter to carry out the integral and compute $\mathbf{M}$ from observations; however, the resulting $\mathbf{M}$ transport generally has a divergent component, although it must be horizontally nondivergent because of stationarity:

$$
\nabla \cdot \mathbf{M}=0
$$

Freshwater sources at the surface (evaporation and precipitation) are neglected here on account of their small values relative to observed oceanic transports' uncertainties. To implement the nondivergence constraint (6) and correct the value of $\mathbf{M}$ given by the depth integral in (5), we introduce the streamfunction $\psi(\lambda, \theta)$ :

$$
\begin{aligned}
& M_{\lambda}=-\frac{1}{a} \partial_{\theta} \psi \\
& M_{\theta}=\frac{1}{a \cos \theta} \partial_{\lambda} \psi
\end{aligned}
$$

with $a$ as Earth's radius and $\lambda, \theta$, as the longitude and latitude, respectively. When $\mathbf{M}$ is known, the equation obeyed by $\psi$ in the Cartesian coordinates $(\lambda, \theta)$ is simply

$$
\frac{\partial^{2} \psi}{\partial \lambda^{2}}+\frac{\partial^{2} \psi}{\partial \theta^{2}}=a\left[\partial_{\lambda}\left(M_{\theta} \cos \theta\right)-\partial_{\theta}\left(M_{\lambda}\right)\right]
$$

This is a Poisson equation forced on the right-hand side by the curl of the vector $\mathbf{m}=\left(a M_{\lambda}, a \cos \theta M_{\theta}\right) .{ }^{1}$ On solid boundaries, the normal velocity must vanish. Suppose that the coast is defined by a curve of equation $F(\lambda, \theta)=$ 0 . This is a material curve for the barotropic transport provided:

$$
\mathbf{M} \cdot \nabla F=0 .
$$

By inserting (7) in (9), this becomes

$$
J(\psi, F)=0,
$$

where $J$ is the Jacobian operator in $(\lambda, \theta)$ Cartesian coordinates. Obviously this vanishes if $\psi$ is a constant over the boundary. Once (8) is solved with appropriate boundary conditions on the domain, a corrected, divergence-free, barotropic transport $\mathbf{M}^{*}$ follows from (7). Of course there are also open boundaries (the

\footnotetext{
${ }^{1}$ This is not the curl of $\mathbf{M}$, which is given by $(1 / a \cos \theta)\left[\partial\left(M_{\theta}\right) / \partial \lambda-\partial\left(M_{\lambda} \cos \theta\right) / \partial \theta\right]$ in spherical coordinates.
} 


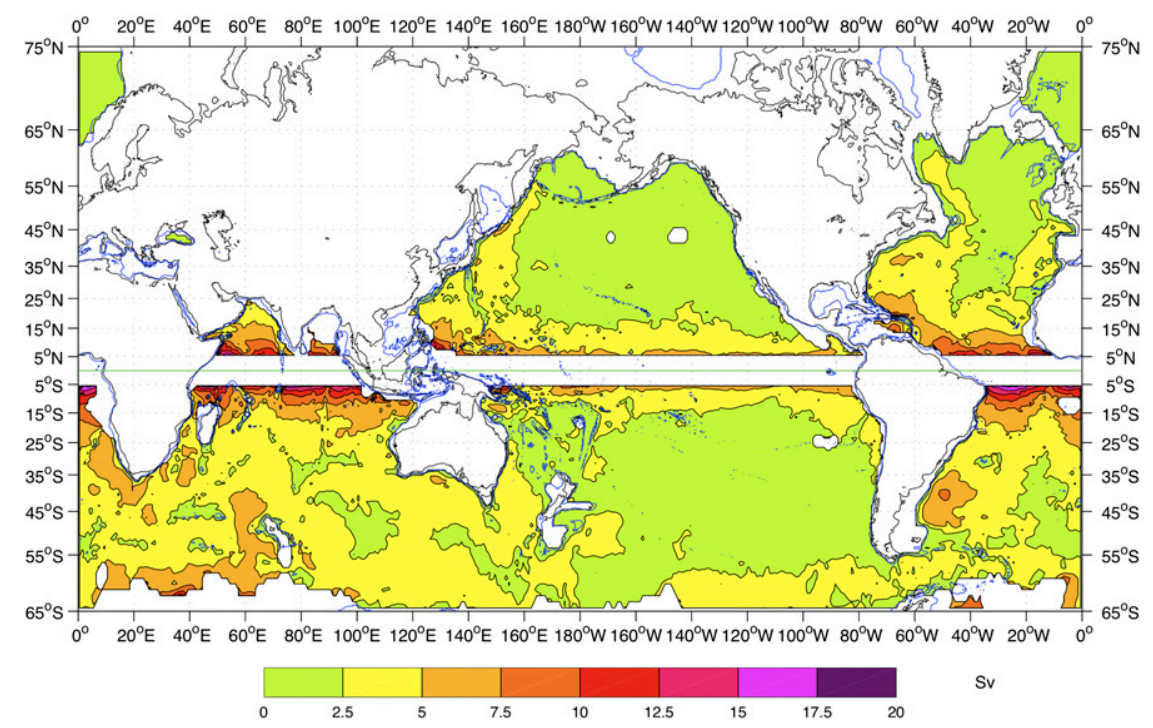

FIG. 1. Standard error on the total transport estimated as $\delta \phi H / f$, with $\delta \phi$ the geopotential error at $1000 \mathrm{db}$ (given in OCV).

excluded equatorial band and at polar latitudes), and every such section becomes a particular case. When our observed transport through an open boundary differs from a transport known otherwise, two procedures have been tested: one is to apply the same correction uniformly to the observed transports, and the other is to impose the required net transport by modifying only the barotropic transport of the westernmost grid point of a zonal section. There are two justifications for this choice. Our method is based on geostrophy, and we know that this hypothesis becomes incorrect for velocities normal to the coast at western boundaries where barotropic boundary currents occur with new dynamics. So, in effect, we adjust the transport at western boundary points as in the Stommel and Arons's (1960a,b) abyssal theory. Second, the mean western boundary currents are not well sampled by Argo floats either because of shallow depth or just an insufficient number of observations, and so this is one way to correct for this bias. This is a further assumption in our method, and there is no real alternative to the accurate observations of barotropic transports at open boundaries. Implementations of these boundary conditions are detailed in each basin subsection.

\section{b. Errors}

There remains the central question of the accuracy of the method. The errors come from limited time averaging and therefore contamination of the mean circulation by the mesoscale eddies. We do not discuss the WOA 2009 time-averaged temperature and salinity errors that can be found in Antonov et al. (2010) and Locarnini et al. (2010), respectively. We concentrate on the propagation of errors from the time-mean Argo float velocities to the barotropic transports; OCV estimated the error in their time-averaged geopotential at $1000 \mathrm{db}$ by running Monte Carlo trials where the mesoscale sampling error on the time-mean velocity was imposed at each grid point as the observed standard deviation multiplied by a random variable drawn from a uniform distribution between -1 and +1 . The resulting error at each position was defined as the rms of the resulting geopotential values. The result (OCV, their Fig. 18) was encouraging because vast regions in the oceanic interior showed errors less than $\pm 1 \mathrm{~cm}$ (doubling in eddy-rich regions), which seems indeed a very small error. Note that we integrate velocity to obtain geopotential that increases the signal over noise ratio by a factor of $L / \Delta x$, with $L$ as the scale of the mean flow and $\Delta x$ as the scale of the mesoscale error (the $1^{\circ}$ grid size). The consequences for the barotropic transport errors follows: a geopotential height error $\Delta \eta(=1 \mathrm{~cm})$ produces a velocity error over a grid scale $\Delta u=(g / f) \Delta \eta / \Delta x$ and a barotropic streamfunction error $\Delta \psi=\Delta x H \Delta u=$ $(g H / f) \Delta \eta \sim 4 \mathrm{~Sv}$ for a fluid depth $H=4 \mathrm{~km}$ and $f=$ $10^{-4} \mathrm{~s}^{-1}$. This conversion factor $g H / f$ can then be used to transform the geopotential error map in OCV into a barotropic streamfunction error shown in Fig. 1. Outside the equatorial band, the error originating from the Argo float reference level is less than $\pm 5 \mathrm{~Sv}$ over much of the World Ocean.

\section{c. The problem of islands}

In a simply connected domain (fluid enclosed by a single boundary curve), $\psi$ is a constant that can be set 
arbitrarily to zero. In a multiply connected domain (with islands), (10) still applies on each island boundary, but the value of $\psi$ remains undetermined. In early primitive equation models with a rigid lid, the barotropic vorticity equation had to be solved at each time step and exactly the same difficulty arose. The difficulty was overcome by Kamenkovitch (1962) in his discussion of the Antarctic Circumpolar Current who proposed a solution (also used in rigid-lid models; Bryan and Cox 1972), which we adapt to the present situation. Suppose first that we have a domain $D$ with vorticity $\zeta$ inside a boundary $\partial D$ and a single island $I$ with boundary $\partial I_{1}$. Because this is a linear problem, we can write the solution as a linear combination of two auxiliary problems:

$$
\psi=\psi_{0}+\mu_{1} \psi_{1}
$$

where $\psi_{0}$ obeys

$$
\nabla^{2} \psi_{0}=\zeta \quad \text { with } \quad \psi_{0}=0 \quad \text { on } \quad \partial D \text { and } \partial I_{1}
$$

and $\psi_{1}$ obeys

$$
\begin{gathered}
\nabla^{2} \psi_{1}=0 \quad \text { with } \psi_{1}=0 \text { on } \partial D \\
\text { and } \psi_{1}=1 \text { on } \partial I_{1} .
\end{gathered}
$$

To determine $\mu_{1}$, we impose that the circulation around the island is conserved so that

$$
\int_{\partial I_{1}} \mathbf{k} \times \nabla \psi \cdot d s=\int_{\partial I_{1}} \partial_{n} \psi d s=\int_{\partial I_{1}} \mathbf{m} \cdot d s .
$$

Using (11), this becomes a condition on the value of $\mu_{1}$ :

$$
\mu_{1} \int_{\partial I_{1}} \partial_{n} \psi_{1} d s+\int_{\partial I_{1}} \partial_{n} \psi_{0} d s=\int_{\partial I_{1}} \mathbf{m} \cdot d s .
$$

The method generalizes itself to the case of $N$ islands. We define $\psi$ as

$$
\psi=\psi_{0}+\sum \mu_{k} \psi_{k}
$$

with

$$
\begin{aligned}
& \nabla^{2} \psi_{k}=0 \text { with } \psi_{k}=0 \text { on } \partial D \cup \partial I_{j} \\
& \text { for } j \neq k \text { and } \psi_{k}=1 \text { on } \partial I_{k}, \text { and } \\
& \nabla^{2} \psi_{0}=\zeta \text { with } \psi_{0}=0 \text { on } \partial D \cup \partial I_{j} \text { for all } j .
\end{aligned}
$$

Then we enforce that the circulation around each island equals the observed circulation:

$$
\begin{aligned}
& \sum_{j} \mu_{j} \int_{\partial I_{k}} \partial_{n} \psi_{j} d s+\int_{\partial I_{k}} \partial_{n} \psi_{0} d s=\int_{\partial I_{k}} \mathbf{m} \cdot d s \\
& \text { for } \quad k=1 \ldots N .
\end{aligned}
$$

Equation (19) is a linear system of $N$ equations with the $N \mu_{k}$ as unknowns whose inversion provides the $N$ values of the streamfunction on each island.

\section{d. The numerical method}

The first important task is to decide what is considered an island in the dataset. Indeed there are areas where the ANDRO database is too sparse and no mean velocity has been recorded. Such data holes are filled by linear interpolation. But, of course, there are also very small islands, and these have been treated similarly by linear interpolation. This is the case for the Northern Hemisphere. The Arctic basin is excluded from the computational domain, and the net flows around Greenland and Iceland are imposed. The Gulf of Mexico and the Antilles Arcs are not considered either. In the Southern Hemisphere, however, four large islands have been kept, namely, Madagascar, the Kerguelen Plateau, New Zealand, and the Antarctic continent. The numerical methods are similar to those used by OCV. The only difference is that they solved a Poisson equation with Neumann boundary conditions, whereas the present problem has Dirichlet boundary conditions. The variables $M_{\lambda}, M_{\theta}$, and $\psi$ are discretized on the same staggered D grid, and the $N+1$ Poisson equations (17) and (18) for the $N$ islands case are solved as the asymptotic, large time limit of the corresponding diffusion equation. The linear system [(19)] is then constructed by computing the various circulation integrals, and its inversion gives the boundary values of $\psi$ over the chosen islands. The final step is to sum up the various contributions from (16).

\section{Vorticity theory and the Sverdrup relation}

We examine here the depth-integrated vorticity equation and discuss the Sverdrup relation. Once we know the barotropic transports $\mathbf{M}^{*}$ that satisfy lateral boundary conditions, we may test the validity of the Sverdrup relation. The derivation of (23) is standard (see Holland 1972; Mellor et al. 1982; Greatbatch et al. 1991). The momentum equation [(5)] is rewritten for the new barotropic transport as

$$
f \mathbf{k} \times \mathbf{M}^{*}=-\int_{-H}^{0} \nabla p^{*} d z+\tau \quad \text { with } \quad \mathbf{M}^{*}=\mathbf{k} \times \nabla \psi .
$$

A new corrected pressure $p^{*}$ has to be introduced since the Coriolis terms have changed between (5) 
and (20). We transform first the pressure gradient term as

$$
\int_{-H}^{0} \nabla p^{*} d z=\nabla \xi-p^{*}(-H) \nabla H \quad \text { where } \quad \xi=\int_{-H}^{0} p^{*} d z
$$

so that (20) becomes

$$
\begin{gathered}
-f M_{0}^{*} \cos \theta=\frac{1}{a} \partial_{\lambda} \xi+p^{*}(-H) \frac{1}{a} \partial_{\lambda} H+\tau_{\lambda} \cos \theta, \\
f M_{\lambda}^{*}=-\frac{1}{a} \partial_{\theta} \xi+p^{*}(-H) \frac{1}{a} \partial_{\theta} H+\tau_{\theta} .
\end{gathered}
$$

To eliminate the gradient term, we take the curl by cross differentiation of (22a) and (22b):

$$
\beta M_{\theta}^{*}=J\left[p^{*}(-H), H\right]+\nabla \times \tau,
$$

which is the Sverdrup relation modified by the presence of the bottom pressure torque on the right-hand side caused by bottom pressure variations on the seafloor. Here, $\beta=\partial_{\theta} f l a, J\left(p^{*}, H\right)=\left(\partial_{\lambda} p^{*} \partial_{\theta} H-\partial_{\theta} p^{*} \partial_{\lambda} H\right) /\left(a^{2} \cos \theta\right)$, and $\nabla \times \tau$ is similar to $\nabla \times \mathbf{M}$ given in footnote 1 . Although we do not have direct access to $p^{*}$, the momentum equation [(20)] allows us to obtain the vertically integrated pressure gradient from the knowledge of $\mathbf{M}^{*}$. Similarly, the bottom pressure torque is obtained from (23) through the difference of the beta term and the wind stress curl. Here, we touch upon the main difference with Mellor's (1982) method, who obtained the barotropic streamfunction after transforming (23) to

$$
\beta M_{\theta}^{*}=\rho f \mathbf{u}_{G}(-H) \cdot \nabla H+\nabla \times \tau,
$$

using (4) to relate pressure to $\mathbf{u}_{G}$, the bottom geostrophic velocity. Here, we enforce the full lateral boundary conditions for the barotropic flow at the level of the momentum equations and never use the vorticity equation. As will be seen, the beta term $\beta M_{\theta}$ and wind stress curl terms in (23) have a very different spectral content (the meridional transport $M_{\theta}$ term is small scale; the curl of the wind stress is large scale) so that to improve the signal over noise ratio, we set up the comparison between these two fields at the level of streamfunction, as in Hautala et al. (1994), and compute a Sverdrup streamfunction $\psi_{S}$ by integrating the wind stress curl from an eastern coast as

$$
\psi_{S}(\lambda, \theta)=\psi\left(\lambda_{E}, \theta\right)+\frac{1}{\beta} \int_{\lambda_{E}}^{\lambda} \nabla \times \tau a \cos \theta d \lambda,
$$

with $\psi\left(\lambda_{E}, \theta\right)$, the value of the imposed streamfunction at longitude $\lambda_{E}$ of the eastern coast.
A brief summary of tests of the Sverdrup relation is appropriate here, but see Hautala et al. (1994) and Wunsch $(1996,2011)$ for more extended and instructive discussions. Numerous tests have been carried out at $24^{\circ} \mathrm{N}$ in the North Atlantic (Leetmaa et al. 1977; Wunsch and Roemmich 1985; Schmitz et al. 1992) and in the North Pacific (Hautala et al. 1994). All these studies differ from the present one because in the absence of a reference level, the authors assumed a level of no motion in the [1000-2000]-m range to compute geostrophic velocities. Leetmaa et al. (1977) computed the upperlayer meridional transport $M_{\theta}$ only above a certain depth thought to represent the vertical extent of the wind-driven circulation and concluded to the validity of the Sverdrup relation. Wunsch and Roemmich (1985) pointed out that the $30 \mathrm{~Sv}$ of upper-layer Sverdrup transport and return of the same quantity at Florida Straits were inconsistent with the value of heat transport at $24^{\circ} \mathrm{N}$, an issue resolved later by Schmitz et al. (1992). A second more difficult objection put forward by Wunsch and Roemmich (1985) was that the vertical velocity must also be zero at the maximum depth where transport is computed, when the meridional transport proceeds from the surface to some intermediate depth $z^{*}$. Wunsch (2011) calls this a test of Sverdrup balance (rather than Sverdrup relation). When the Sverdrup balance is valid, the vertical velocity necessarily vanishes under geostrophic assumptions (Hautala et al. 1994). So the test of Sverdrup balance becomes a search for the depth where the balance is valid, hence a depth of no vertical motion. Two tests of Sverdrup balance using absolute velocities have appeared recently; Wunsch (2011) used the 1992-2007 time average of the timevarying ocean circulation ECCO model estimate with data constraints including altimetry, CTD and XBT data, and Argo and elephant seals profiles (but no Argo float parking depth velocities) and tested Sverdrup balance by choosing a depth $z^{*}$ where the vertical velocity could be neglected $\left(<10^{-8} \mathrm{~m} \mathrm{~s}^{-1}\right)$, usually in the range $1000-1500 \mathrm{~m}$. This test of Sverdrup balance was generally positive in the interior of the subtropical gyres and in the tropics away from the equator. With the Argo float displacements at 1000 and $1500 \mathrm{db}$ and Argo temperature-salinity profiles up to $2000 \mathrm{db}$, Gray and Riser (2014) reconstructed geopotential using statistical objective analysis. Although a large part of the data that they used is similar to ours, the methods differ and their geopotential at $1000 \mathrm{~m}$ (Gray and Riser 2014, their Fig. 4) is very different (much smoother) from that found in OCV (their Fig. 16a). Gray and Riser tested Sverdrup balance by varying $z^{*}$ and found the best agreement for latitudes equatorward of $\pm 30^{\circ}$ but rather shallow depths (much less than $1000 \mathrm{db}$ ). 
TABLE 1. Transport boundary conditions for the North Atlantic basin.

\begin{tabular}{lc}
\hline \hline \multicolumn{1}{c}{$\begin{array}{c}\text { North Atlantic basin open } \\
\text { boundary conditions }\end{array}$} & $\begin{array}{c}\text { Imposed transports } \\
\text { (Sv; positive inwards) }\end{array}$ \\
\hline Southern boundary at $5.5^{\circ} \mathrm{N}$ & 0 \\
$61.5^{\circ} \mathrm{W}$ (from $11.5^{\circ}$ to $19.5^{\circ} \mathrm{N}$ ) & -30 \\
Florida Straits $\left(27.5^{\circ} \mathrm{N}\right.$ ) & 30 \\
Northern boundary at $62.5^{\circ} \mathrm{N}$ (from & -4.7 \\
$24.5^{\circ}$ to $9.5^{\circ} \mathrm{W}$ ) & 4.7 \\
Northern boundary at $28.5^{\circ} \mathrm{W}$ (from & \\
$62.5^{\circ}$ to $65.5^{\circ} \mathrm{N}$ ) & \\
\hline
\end{tabular}

\section{The North Atlantic}

The North Atlantic basin is used as a test case to present the results of the new method in some details and discuss Sverdrup relation. The boundary conditions at open boundaries of the North Atlantic basin are gathered in Table 1 . The value of the streamfunction at the open southern boundary at $5.5^{\circ} \mathrm{N}$ is simply obtained by integrating the observed meridional transport $M_{\theta}$ as a function of longitude. Since we neglect the $O(1) \mathrm{Sv}$ inflow from the Pacific, the streamfunction has to be zero on both sides of the section. But the observations show instead a $24.5-\mathrm{Sv}$ inflow. The value of the transport at the westernmost grid point is then modified to correct for this imbalance and guarantee a zero net input at the southern boundary. As mentioned earlier we have also tested a uniform correction along the open boundary. The difference between the two solutions is apparent over a $10^{\circ}$ latitude range north of the open boundary and has the shape of the Green's function of the Laplace equation forced by a line distribution at the boundary. We show only the former case here for the sake of better physics mentioned previously. At the northern boundary we impose a 4.7-Sv exchange with the Arctic basin (as an output west of $24.5^{\circ} \mathrm{W}$ and an input along $28.5^{\circ} \mathrm{W}$ ), a net exchange that is estimated from Talley et al.'s (2011) synthesis (and references therein). The Gulf of Mexico and the Antilles Arc have been suppressed from the domain as the sampling by the Argo floats is poor. Therefore, a 30-Sv outflow is imposed at $61.5^{\circ} \mathrm{W}$ between $11.5^{\circ}$ and $19.5^{\circ} \mathrm{N}$, and the same quantity enters at Florida Straits. Because the Blake Bahamas Plateau is shallower than the Argo float parking depth, barotropic velocities are imposed on the plateau to account for a 30-Sv transport distributed over two grid points between $28^{\circ}$ and $31.5^{\circ} \mathrm{N}$. After solving the Poisson problem [(8)] with the Dirichlet boundary conditions, we obtain the nondivergent barotropic transports $\mathbf{M}^{*}$ with (7) and calculate the difference with the initial transports $\mathbf{M}$ in Fig. 2. We have divided the transports by the local depth to show barotropic velocities. The

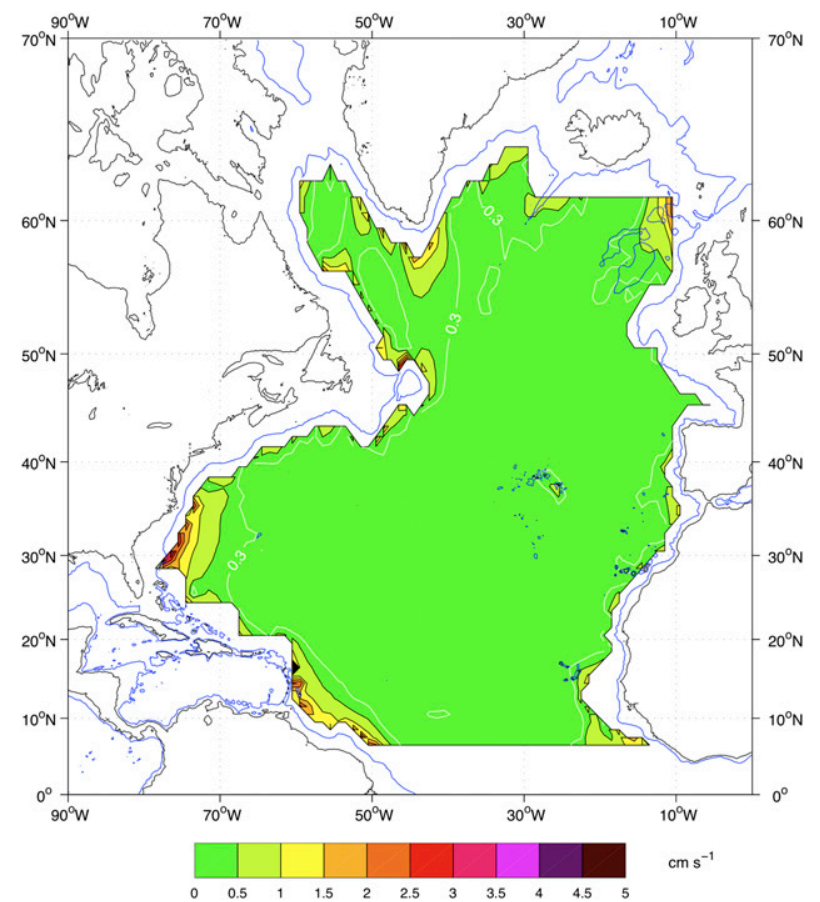

FIG. 2. The modulus of the difference of barotropic velocities $\mid \mathbf{M}^{*}-\mathbf{M} / / \mathrm{H}\left(\mathrm{cm} \mathrm{s}^{-1}\right)$. The white contour indicates a $0.3 \mathrm{~cm} \mathrm{~s}^{-1}$ difference. The 1000-m bathymetric contour is in blue.

rms value of the difference is equal to $0.5 \mathrm{~cm} \mathrm{~s}^{-1}$ for either the meridional or zonal component (this value also applies to other basins in sections 5 and 6 ). The corrections to the original velocities are less than $0.3 \mathrm{~cm} \mathrm{~s}^{-1}$ in the interior but reach several centimeters per second near the boundaries and especially the western boundaries. Obviously most of the spurious divergent barotropic velocities are found there.

The two major cyclonic and anticyclonic gyres stand out in the barotropic streamfunction (Fig. 3). They are isolated with a well-defined boundary straddling the latitudes $50^{\circ}-52^{\circ} \mathrm{N}$. This boundary is well captured by the Sverdrup relation (25). The southern boundary of the subtropical gyre is less defined, and we suspect that the weak gyres in the $10^{\circ}-15^{\circ} \mathrm{N}$ latitude band do not represent correctly the North Brazil Current retroflection and the North Equatorial Countercurrent. The major features of this reconstruction are the two inertial recirculations. The southern anticyclonic one extends from the U.S. coast at $34^{\circ} \mathrm{N}$ to about $45^{\circ} \mathrm{W}$ and has a 72-Sv maximum. The northern cyclonic recirculation has a minimum of $-24 \mathrm{~Sv}$. The time-mean Gulf Stream is a jet between these two recirculations. We estimate the maximum eastward Gulf Stream transport from Fig. 3 with an error $O(5 \approx \sqrt{2} \times 3) \mathrm{Sv}$ from Fig. 1 . It reaches $68 \mathrm{~Sv}$ at $70^{\circ} \mathrm{W}$, increases to about $97.5 \mathrm{~Sv}$ at $60^{\circ} \mathrm{W}$, and decreases to $83 \mathrm{~Sv}$ at $55^{\circ} \mathrm{W}$ (Fig. 4). This evolution of 


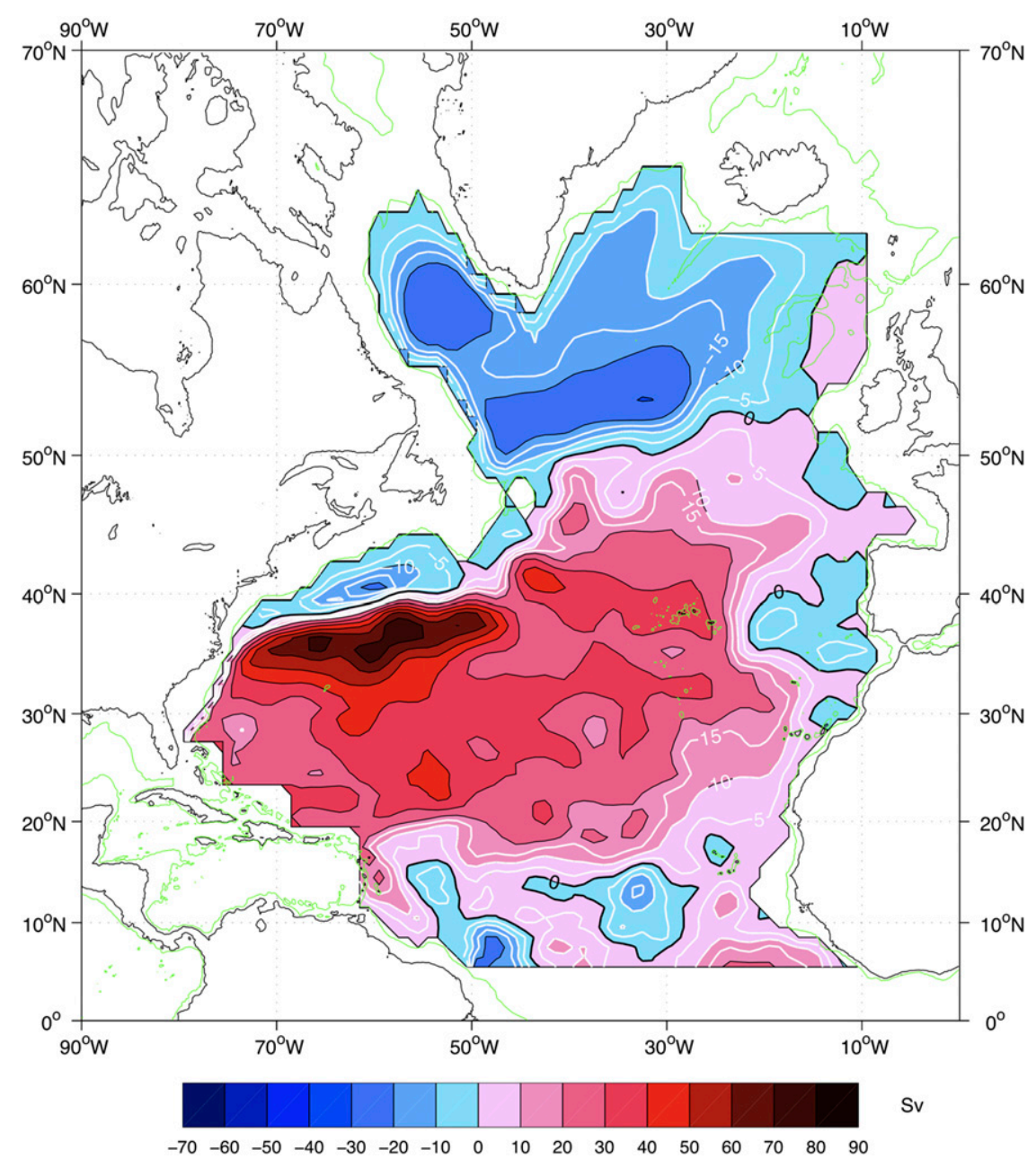

FIG. 3. The North Atlantic barotropic streamfunction (Sv). The nominal contour interval is $10 \mathrm{~Sv}$, but some additional white contours are drawn every $5 \mathrm{~Sv}$. The 1000 -m bathymetric contour is in green.

transport is rather similar to Richardson's (1985) curve but with somewhat smaller transports. Time-mean Eulerian transports from Johns et al. (1995) and Richardson (1985) are $88 \mathrm{~Sv}$ at $68^{\circ} \mathrm{W}$ and $85 \mathrm{~Sv}$ at $55^{\circ} \mathrm{W}$, respectively. Also included in Fig. 4 are the past estimates found in the reviews of Richardson (1985) and Johns et al. (1995). It shows readily the differences between the Eulerian timemean transports (as here) and the much larger synoptic and semi-Lagrangian stream axis transport estimates of Worthington (1976), Hogg (1992), and others. Farther east, the Gulf Stream extension becomes the northern branch of the Mann Gyre (Mann 1967), which reaches here $47.5 \mathrm{~Sv}$. On the eastern side (east of $25^{\circ} \mathrm{W}$ ), there is a cyclonic cell between $32^{\circ}$ and $42^{\circ} \mathrm{N}$ with a marked $25-\mathrm{Sv}$ southward transport. A similar cell was found at $1000 \mathrm{~m}$ in Argo float data by OCV. It appears here to be a westward extension of the cyclonic cell of the Mediterranean outflow described by Lamas et al. (2010), east of $14^{\circ} \mathrm{W}$. The subpolar barotropic gyre appears here as a closed cyclonic cell distinct from the subtropical gyre. North of the $50^{\circ} \mathrm{N}$ boundary, our reconstruction shows a North Atlantic barotropic current that transports about $25 \mathrm{~Sv}$ to the northeast. The streamfunction has two distinct minima around $-30 \mathrm{~Sv}$ in the center of the subpolar gyre $\left(53^{\circ} \mathrm{N}\right.$ and $\left.32^{\circ} \mathrm{W}\right)$ and $-29.5 \mathrm{~Sv}$ in the Labrador basin $\left(59^{\circ} \mathrm{N}\right.$ and $\left.52^{\circ} \mathrm{W}\right)$, which is therefore also the strength of the Greenland Current and Labrador Current, respectively. The deviation by the Reykjanes Ridge is apparent with a 15-Sv deflection. The barotropic streamfunction computed by Mellor et al. (1982) from the vorticity equation (23) shows similarities with the present solution north of $25^{\circ} \mathrm{N}$. The extrema of western boundary inertial recirculations $(-20$ and $60 \mathrm{~Sv})$, the maxima of Gulf Stream transport $(90 \mathrm{~Sv})$, and the minima in the 


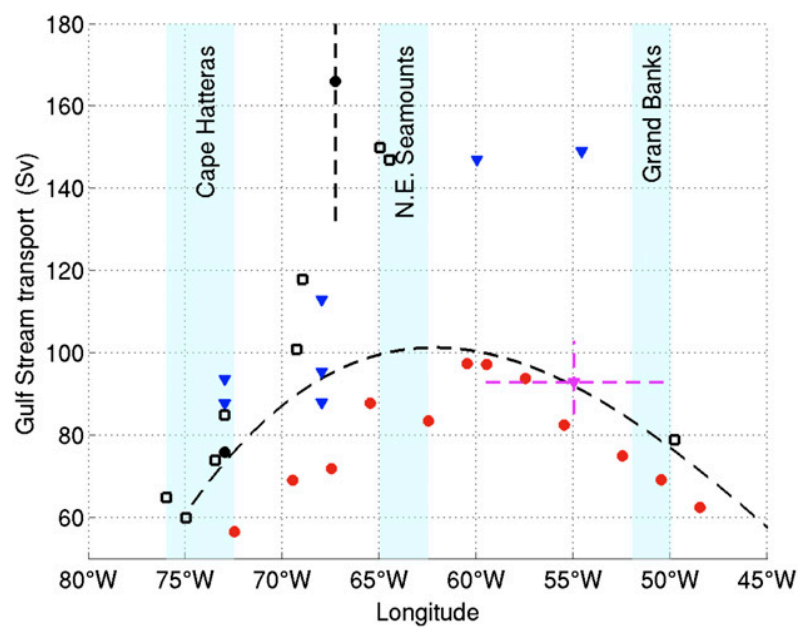

FIG. 4. Gulf Stream transports as a function of longitude (red solid circles) are compared to past estimates taken from reviews by Richardson (1985) and Johns et al. (1995). The dashed curve represents the downstream evolution of time-mean transport from Richardson (1985). The other symbols used represent: black squares - synoptic hydrographic section estimates from Fuglister (1963), Barrett (1965), Warren and Volkman (1968), Worthington (1976), and Clarke et al. (1980); blue diamonds - current-meter and Pegasus estimates from Halkin and Rossby (1985), Leaman et al. (1989), Hogg (1992), and Johns et al. (1995); and black solid circles - transport floats from Knauss (1969) and Barrett and Schmitz (1971), the latter with an error bar \pm 36 Sv (dashed line). The important time-mean estimate of Richardson (1985) at $55^{\circ} \mathrm{W}$ from a combination of surface drifters, SOFAR floats (700 and $2000 \mathrm{~m}$ ), and current meters $(4000 \mathrm{~m})$ is shown in magenta (triangle with error bars).

subpolar gyre reaches $-40 \mathrm{~Sv}$, all values that are in the range of what is found here. The solutions of Bogden et al. (1993) are close to those of Mellor et al. (1982) when they impose $\psi=0$ at the eastern boundary. South of $25^{\circ} \mathrm{N}$, Mellor et al.'s (1982) and Bogden et al.'s (1993) solutions are noisier and exhibit a marked steering along $f / H$ contours. Our solutions are smoother and do not exhibit the $f / H$ steering, but they also depend on the choice of the transport correction made at the open boundary.

A first test of the Sverdrup relation is presented at the streamfunction level by comparing the Sverdrup streamfunction equation [(25)] with the observed one at $24.5^{\circ} \mathrm{N}, 36.5^{\circ} \mathrm{N}$, and $56.5^{\circ} \mathrm{N}$ where many tests of Sverdrup theory have been carried out (Fig. 5). There is very roughly a factor of 2 difference between the Sverdrup and the observed streamfunction that shows more zonal structure. The observed streamfunction is larger than the Sverdrup streamfunction in the subtropical gyre, which means that the bottom torque reinforces the wind stress curl in (23). This result is true of all oceans (see Figs. 7 and 9). The Sverdrup prediction is somewhat better in the subpolar gyres at $56.5^{\circ} \mathrm{N}$, but again more structure is found in the observed streamfunction. The predicted values by the Sverdrup streamfunction are about right $(25 \mathrm{~Sv})$ in the Labrador basin but the southwestward current directions only agree in the area $54^{\circ}-57^{\circ} \mathrm{N}$ and $45^{\circ}-30^{\circ} \mathrm{W}$. Note that the boundary between the subtropical and subpolar gyres in Fig. 3 is very well captured by the contours of the zero wind stress curl (Fig. 6). Over vast regions, the beta term is much larger than the wind stress curl (Fig. 6), so that the bottom pressure torque term (not shown), computed from (23), is very much like the beta term. As noted earlier, the bottom torque term is on average negative in the subtropical gyre (as the wind stress curl). In a diagnostic study of the region centered around $55^{\circ} \mathrm{N}, 22.5^{\circ} \mathrm{W}$, the importance of the flow along
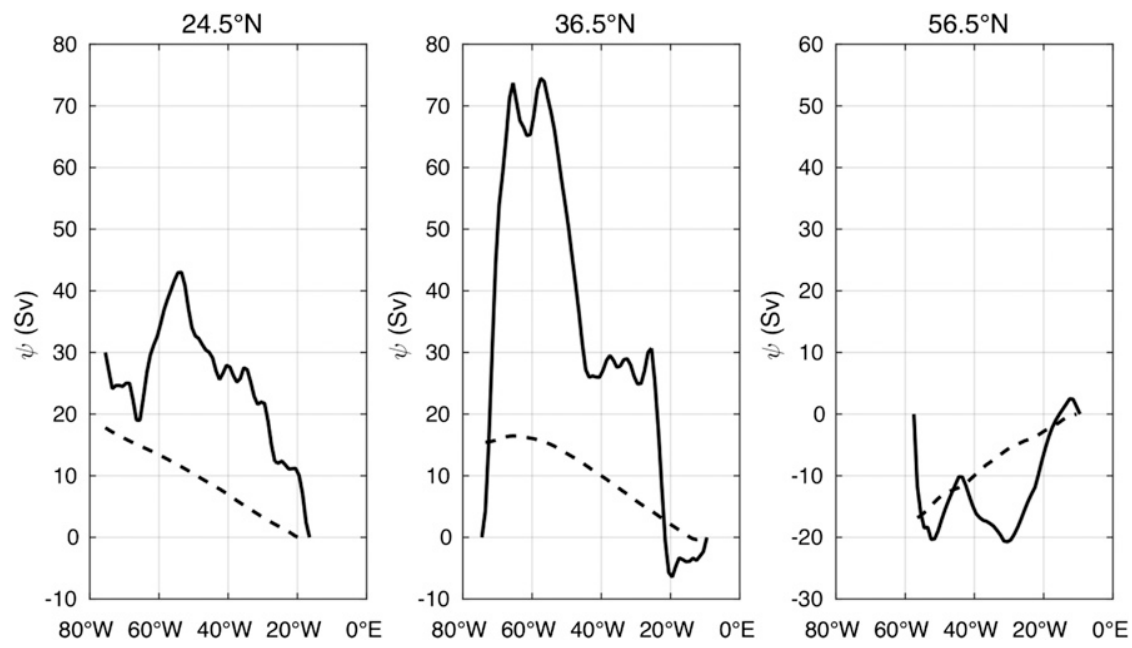

FIG. 5. The comparisons of the observed streamfunctions (solid) in the Atlantic with the Sverdrup streamfunction (dashed) at $24.5^{\circ}, 36.5^{\circ}$, and $56.5^{\circ} \mathrm{N}$. 

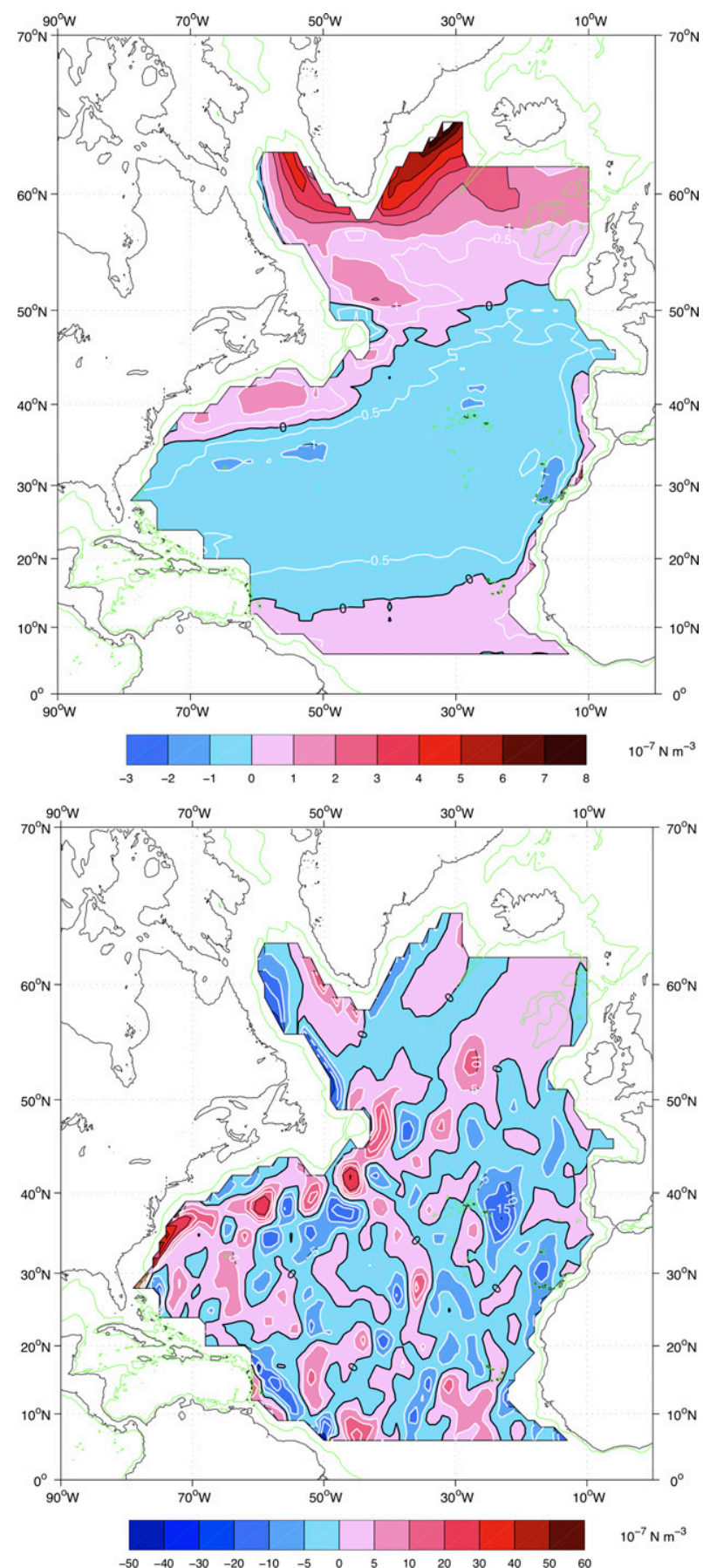

FIG. 6. (a). The wind stress curl $\left(10^{-7} \mathrm{~N} \mathrm{~m}^{-3}\right)$. The black bold contour indicates the zero wind stress curl. Additional white contours are drawn every $0.5 \times 10^{-7} \mathrm{~N} \mathrm{~m}^{-3}$. The 1000 -m bathymetric contour is in green. (b) The term $\beta M_{\theta}\left(10^{-7} \mathrm{~N} \mathrm{~m}^{-3}\right)$. The black bold contour indicates the line of no meridional motion. Additional white contours are drawn every $5 \times 10^{-7} \mathrm{~N} \mathrm{~m}^{-3}$. The $1000-\mathrm{m}$ bathymetric contour is in green. topographic slopes was raised by Luyten et al. (1985), who emphasized that the strong northward transport was strongly influenced by the bottom vertical velocities. Sarkisyan and Ivanov (1971), Holland (1972), Greatbatch et al. (1991), and Hughes and de Cuevas (2001) describe the effects of the bottom torques to boost the gyres in primitive equations model calculations, while Salmon (1994) introduced idealized models to study such dynamics. But there are many other missing terms in (23). We have checked that the advection of relative vorticity is small outside the inertial recirculations. Bottom friction is a significant energy dissipation source [see Arbic et al. (2009) and references therein], but the curl of the bottom stresses computed here with the time-mean bottom flows is at least one to two orders of magnitude less than the wind stress curl in the interior. Contributions from unsteady flows to mountain (form) drag are an open possibility given the broad spectrum of both topography and oceanic motions (mesoscale eddies, internal waves). Difficulties in such estimations in the atmosphere have been explored by Smith (1978), who emphasizes the topographic scales that need to be resolved for reliable estimates of the mountain drag. Because the spectrum of topographic slopes in the ocean is typically white at wavenumbers between $10^{-2}$ and 10 cycles km${ }^{-1}$ (Bell 1975), the question of the choice of topography and velocity to be used for the evaluation of the bottom pressure torque is rather similar here.

\section{The North Pacific}

The open southern boundary in the North Pacific has been shifted to $10.5^{\circ} \mathrm{N}$ essentially because of the complexity of the western boundary south of that latitude. The observations give there a northward transport of $48 \mathrm{~Sv}$. As previously, the meridional velocity at the western end of the section is modified to absorb this imbalance by a western boundary current with an equivalent transport to the south. This condition of zero net transport neglects a possible passage to the Indonesian Throughflow via the South China Sea between $19^{\circ}$ and $21^{\circ} \mathrm{N}$ and the Bering Strait outflow. The three gyres, tropical, subtropical and subpolar, found by Munk's (1950) early wind-driven calculations are easily recognized in Fig. 7. The boundary of the subtropical gyre is marked by a strong zonal westward north equatorial current carrying about $40 \mathrm{~Sv}$ between $10^{\circ}$ and $14^{\circ} \mathrm{N}$. Along $137^{\circ} \mathrm{E}$ and from $10.5^{\circ}$ to $24.5^{\circ} \mathrm{N}$, the westward transport reaches $67 \mathrm{~Sv}$ as compared to $59.4 \mathrm{~Sv}$ estimated by Qiu and Joyce (1992) for transport above $1000 \mathrm{~m}$. South of Japan, the Kuroshio transport maximum is $62 \mathrm{~Sv}$ at $136.5^{\circ} \mathrm{E}$ and increases to $88 \mathrm{~Sv}$ at 


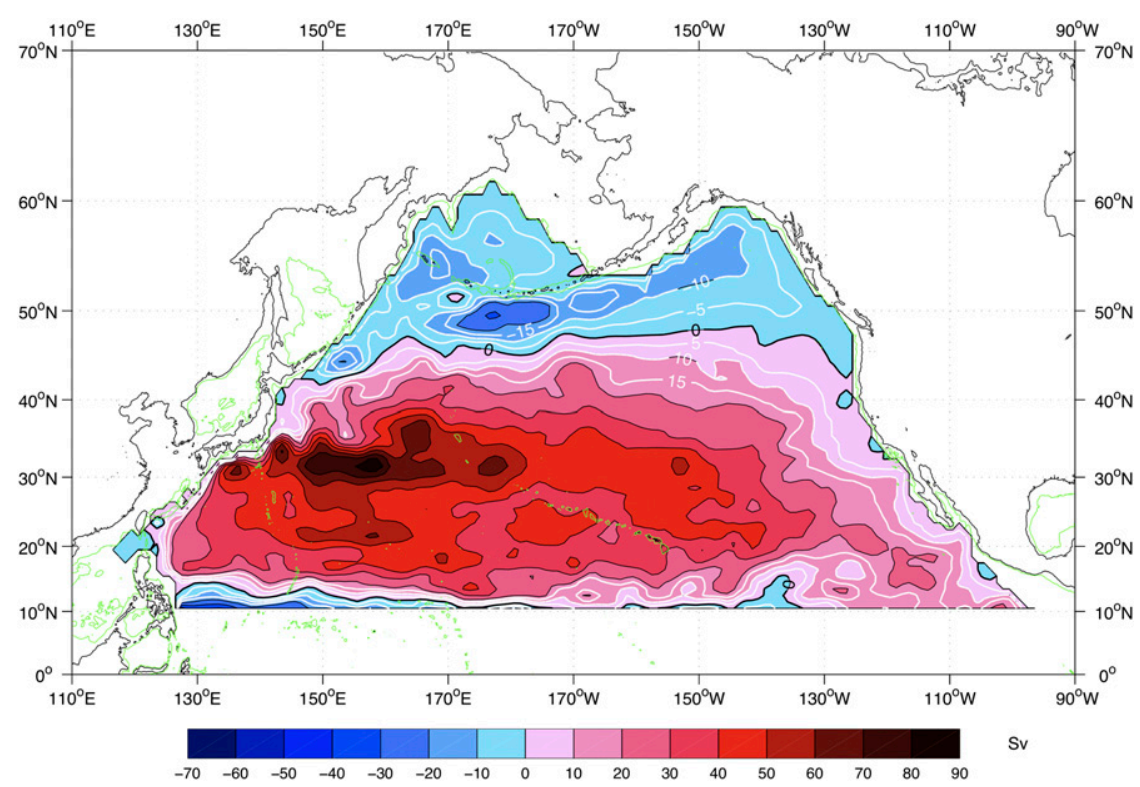

FIG. 7. The North Pacific barotropic streamfunction (Sv). The black contour interval is $10 \mathrm{~Sv}$. Additional white contours are drawn every $5 \mathrm{~Sv}$. The $1000-\mathrm{m}$ bathymetric contour is in green.

$157.5^{\circ}$ E. Qiu and Joyce (1992) estimate a 52.4-Sv Kuroshio transport at $137^{\circ} \mathrm{E}$, and Imawaki et al. (2001) estimates a 57-Sv time-mean Kuroshio transport near $134^{\circ} \mathrm{E}$. As these two estimates only include flow above $1000 \mathrm{~m}$, the transport in the same depth interval was computed using the baroclinic-barotropic decomposition as $45.5 \mathrm{~Sv}$. Note the undulations of the northern wall of the Kuroshio induced by the topographic ridges there. The absence of a northern cyclonic recirculation (as compared to the North Atlantic) is also conspicuous. Differences with Reid's (1997) transport maps (deduced from an ensemble of selected hydrographic sections) are numerous. Neither his eastward flow around $25^{\circ} \mathrm{N}$ nor the large $\mathrm{C}$ shape between $20^{\circ}$ and $40^{\circ} \mathrm{N}$ in the central Pacific are found here. The cyclonic tongue in the eastern North Pacific (across $40^{\circ} \mathrm{N}$ ) is not seen either, a result we attribute to the very laminar flow to the northeast revealed by the Argo floats mean velocities.

On the whole the comparison of the observed flow with Sverdrup theory is somewhat better in the Pacific than in the North Atlantic (Fig. 8). The rate of variation
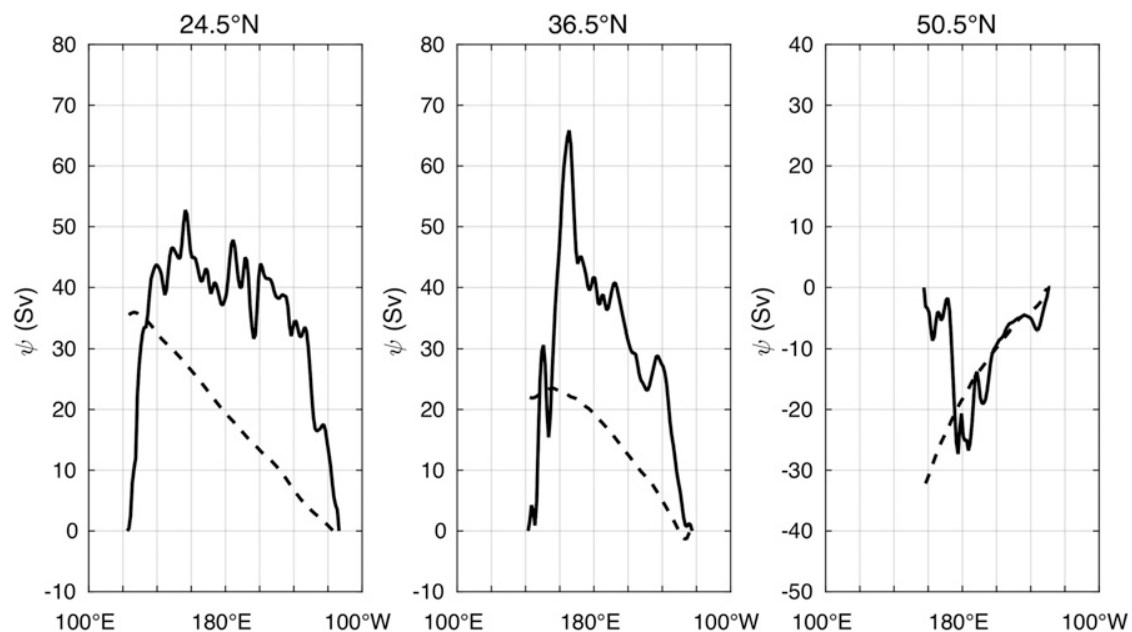

FIG. 8. The comparisons of the observed streamfunctions (solid) in the North Pacific with the Sverdrup streamfunction (dashed) at $24.5^{\circ}, 36.5^{\circ}$, and $50.5^{\circ} \mathrm{N}$. 
TABLE 2. Transport boundary conditions for the Southern Ocean.

\begin{tabular}{lc}
\hline \multicolumn{1}{c}{ Southern Ocean boundary conditions } & $\begin{array}{c}\text { Transports (Sv; } \\
\text { positive inwards) }\end{array}$ \\
\hline Imposed open northern boundary at $9.5^{\circ} \mathrm{S}$ & \\
Streamfunction value over Australia & -15 \\
Pacific transport & -15 \\
Indian transport & 15 \\
Atlantic transport & 0 \\
Computed Streamfunction value over islands & \\
Madagascar & -13 \\
Kerguelen Plateau & 132 \\
New Zealand & -37 \\
Antarctic continent & 175 \\
\hline
\end{tabular}

of the observed streamfunction is still larger than the Sverdrup one in the interior of the subtropical gyre, very much as in the North Atlantic, with identical conclusions for the importance of the bottom pressure torque. Observations and Sverdrup predictions are better in the subpolar gyre. The minima in the subpolar gyre $(-32 \mathrm{~Sv})$ at $49.5^{\circ} \mathrm{N}$ and $177.5^{\circ} \mathrm{E}$ has to be compared with the Sverdrup value of $-20 \mathrm{~Sv}$. A possible cause for this somewhat better comparison is the weakness of the bottom flow in the eastern North Pacific at latitudes greater than $25^{\circ} \mathrm{N}$. The bottom velocities of the order of millimeters per second are among the smallest of the World Ocean (along with the eastern South Pacific between $25^{\circ}$ and $45^{\circ} \mathrm{S}$ ) and should therefore induce negligible vertical velocities at the bottom (hence bottom pressure torque).

\section{The Southern Ocean}

The calculation of the barotropic streamfunction is more involved in the Southern Ocean because the domain is multiply connected. We have included four islands in the computational domain: the Antarctic continent itself, Madagascar, the Kerguelen Plateau,

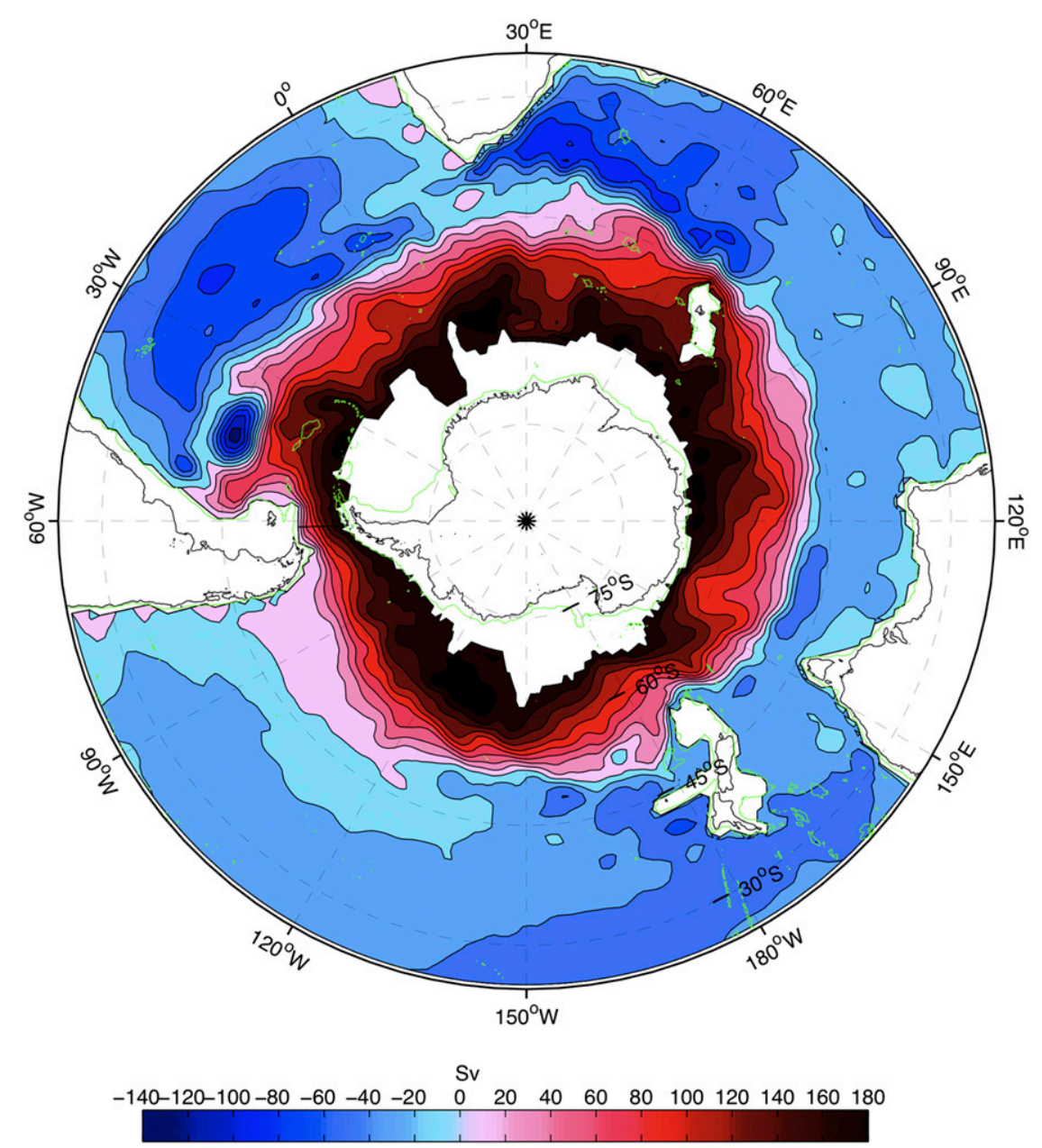

FIG. 9. The Southern Hemisphere barotropic streamfunction (Sv). The contour interval is $20 \mathrm{~Sv}$. The 1000-m bathymetric contour is in green. 

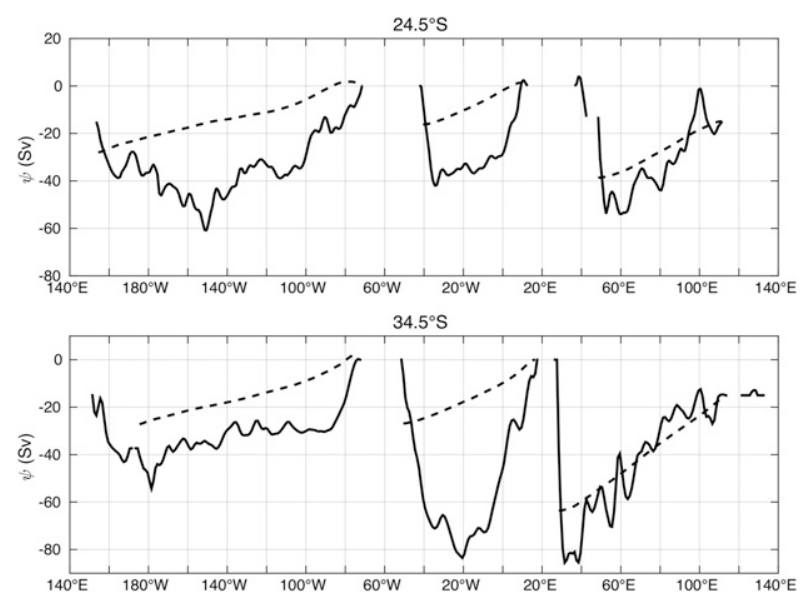

FIG. 10. The comparisons of the observed streamfunctions (solid) in the Southern Ocean with the Sverdrup streamfunction (dashed) at $24.5^{\circ} \mathrm{S}, 34.5^{\circ} \mathrm{S}$.

and New Zealand. All other islands and data holes have been filled by linear interpolations. The values of the streamfunction on these islands represent four additional unknowns that are obtained as part of the solution from the observed circulation around each. Five solutions of a Poisson equation under five different Dirichlet boundary conditions are needed to collect the parts of the full streamfunction including the island values (see section 2). The northern boundary has been chosen at $9.5^{\circ}$ S. Sprintall et al.'s (2009) recent estimate of $15 \mathrm{~Sv}$ for the total Indonesian Throughflow is imposed as a net northward flow at the Pacific boundary and a net southward flow at the Indian Ocean boundary. Australia is not treated as an island as no flow passage is allowed north of Australia and a streamfunction value of $-15 \mathrm{~Sv}$ is imposed there. On the Atlantic, Indian, and Pacific open boundaries at $9.5^{\circ} \mathrm{S}$, we have used the same procedure as before by modifying only the value of the meridional flow of the westernmost grid point to satisfy the transport constraints. All other values along these three open sections are original observed values. At the suggestion of a reviewer, we have also tested a solution in which the Indonesian Throughflow is imposed with uniform corrections along the Indian and Pacific sections of the open boundary. As for the North Atlantic test (section 4), differences in the solutions are limited to a $10^{\circ}$ latitude range south of the boundary. The Madagascar Island value decreases (from -13 to $-22 \mathrm{~Sv}$ ), but no significant modifications are found elsewhere. The overall computation gives the values of the streamfunction over the four islands in Table 2. The Madagascar Island value gives directly the $13-\mathrm{Sv}$ southward flow of Indian Ocean water in the Mozambique Channel that is in the range of the mean value of 8.6 Sv found in the current-meter arrays of Harlander et al. (2009) and the $14 \mathrm{~Sv}$ from Ridderinkhof and de Ruijter (2003). This favorable comparison led us to keep the first choice of the western boundary corrections at $9.5^{\circ} \mathrm{S}$. The net transport of the ACC between the tip of southern America or South Africa and the Antarctic continent is $175 \mathrm{~Sv}$. The transport between Australia and the Antarctic continent is stronger since we have to add the return of the Indonesian Throughflow or $175+15=$ $190 \mathrm{~Sv}$ (since Australia has a boundary condition of $-15 \mathrm{~Sv}$ ). The streamfunction value found over New Zealand $(-37 \mathrm{~Sv})$ is $30 \%$ larger than the estimates derived under Sverdrup dynamics and Godfrey's (1989) island rule (-29Sv) and Risien and Chelton (2008) $(-26 \mathrm{~Sv})$. The total streamfunction for the Southern Hemisphere (Fig. 9) reveals the strongest subtropical gyre in the southern Indian Ocean with a low of $-103 \mathrm{~Sv}$ just north of the ACC, then, in order of decreasing strength, the Atlantic and the Pacific Gyres. The transport of the Agulhas Current is $60 \mathrm{~Sv}$ at $30^{\circ} \mathrm{S}$ and increases to about $90 \mathrm{~Sv}$ at $36^{\circ} \mathrm{S}$. For comparison, Bryden et al. (2005) estimate a transport of $69 \mathrm{~Sv}$ (standard deviation $21.5 \mathrm{~Sv}$ ) from a 267 -day mean of current-meter moorings between $31^{\circ}$ and $32^{\circ} \mathrm{S}$. The downstream increase of the Agulhas transport up to $100 \mathrm{~Sv}$ at $36^{\circ} \mathrm{S}$ from Casal et al. (2009) is more important, but it comes from a 2-month synoptic survey. The southward transport off Brazil computed from the coast to the next extrema of the adjacent gyre (hence over a large width) is $30 \mathrm{~Sv}$ at $20^{\circ} \mathrm{S}$ and about $50 \mathrm{~Sv}$ at $30^{\circ} \mathrm{S}$. The northward flow of the western boundary current at $52.5^{\circ} \mathrm{S}$ off New Zealand reaches $44 \mathrm{~Sv}$. The streamfunction underscores the singularity of the Zapiola Gyre and its strong barotropic signature. Its center at $44.5^{\circ} \mathrm{S}, 42.5^{\circ} \mathrm{W}$ is associated with a $124-\mathrm{Sv}$ maximum transport. Direct bottom current measurements in the area were first made on a WOCE section by Saunders and King (1995), who suggested that the transport could be in excess of $100 \mathrm{~Sv}$. Its dynamics were studied by Dewar (1998) and de Miranda et al. (1999) with the view that the gyre is eddy driven along the closed potential vorticity contours caused by the Zapiola drift, a 1100-m-high significant topographic bump. With values of the transport controlled by the equilibrium between eddy fluxes and bottom friction, our determination could be used to tune the bottom friction. The barotropic circulation of the ACC is of course the major product of the reconstruction. The ACC narrows down and therefore accelerates at several key points: the Drake Passage, north of the Kerguelen Plateau, and north of the Ross Gyre. The largest part (132 Sv) flows north of the Kerguelen Plateau while a branch $(175-132=43 \mathrm{~Sv})$ flows south of the plateau. By comparison, Park et al. (2009) have shown that $92 \mathrm{~Sv}$ of 
the ACC flows north of the Kerguelen Plateau and $58 \mathrm{~Sv}$ south. Between New Zealand and the Antarctic continent, a strong transport of $175+37=212 \mathrm{~Sv}$ is also observed. Also worth mentioning is the $147.5^{\circ} \mathrm{W}$ longitude section that marks the western end of the Ross Gyre. The 175-Sv Drake Passage transport has to be compared with the following estimates: Reid's (1997) 130-Sv hydrographic estimate; Nowlin and Klinck's (1986) $134 \mathrm{~Sv}$ (the first estimate from current-meter data); and the new estimates from International Southern Ocean Studies (ISOS) current-meter data reviewed by Cunningham et al. (2003) at $134 \mathrm{~Sv}$ or inverse model estimations that yield $142 \mathrm{~Sv}$ (MacDonald and Wunsch 1996), 140 Sv (Ganachaud and Wunsch 2000), and $135 \mathrm{~Sv}$ (Sloyan and Rintoul 2001). Gille (1997) also estimated a 121-Sv transport from a combination of ALACE floats measurements and hydrography. Koenig et al. (2014) estimate a transport of $141 \mathrm{~Sv}$ with a long-term variability of $13 \mathrm{~Sv}$ using a combination of hydrography, current-meter estimates, and satellite altimetry. Our global estimate transport of the ACC is therefore about $17 \%$ stronger than Koenig et al.'s (2014) recent local determination. Recently larger values (153 Sv) were estimated by Mazloff et al. (2010). This last comparison is interesting because their barotropic streamfunction estimates come from data and methods completely different from ours. They use an adjoint method to constrain the MIT primitive equations model over 2 yr, 2005/06, by Argo float temperature salinity profiles, CTD synoptic sections, CTD mounted on southern elephant seals, XBTs, and altimetry. Finally the results of a $4 \mathrm{yr}$, intensive experiment at Drake Passage by Donohue (2015) give a total transport of $170 \mathrm{~Sv}$, close to the present value. Our method is global so that the velocities observed over the whole domain contribute to Drake Passage transport, but our estimate may suffer from the poor Argo coverage near the Antarctic continent (the westward return flows of the Ross and Weddell Gyres).

The comparison of observed and Sverdrup streamfunctions is only possible at latitudes where continents block the flow so that zonal pressure gradients can be established. At $24.5^{\circ}$ and $34.5^{\circ} \mathrm{S}$, we see in Fig. 10 that as in the Northern Hemisphere subtropical basins, the Sverdrup transport is small compared to observations roughly by a factor of 2 . The comparison is more satisfactory in the south Indian basin. Farther south the comparison becomes meaningless. Instead the expected dynamics at free latitudes is as follows: If one integrates along a latitude circle the zonal momentum equation [(22a)] around the globe, there remains only

$$
\oint p(-H) \partial_{\lambda} H d \lambda+\oint \tau_{\lambda} a \cos \theta d \lambda=0
$$

The circulation of the zonal wind around the Antarctic continent is balanced by the topographic form drag since the pressure gradient and the Coriolis meridional transport terms vanish. Under our geostrophic hypothesis, the circulation of the wind along that closed streamline gives directly the integrated topographic form drag. Suggested by Munk and Palmen (1951), this relation has received support from model analysis by Gille (1997) and Stevens and Ivchenko (1997). It is further discussed from a theoretical point of view by Olbers et al. (2004). Eddy kinetic energy is very important in the Southern Ocean, yet most models' analysis indicates that the direct contribution of the divergence of the Reynolds stresses [missing in (26)] is not important. The main role of the eddies is to transfer the momentum input by the wind downward to the bottom where topographic form drag can equilibrate the wind (Johnson and Bryden 1989).

\section{Conclusions}

We have shown how the combined knowledge of the Argo float displacement reference level at $1000 \mathrm{db}$ (ANDRO database) and a temperature-salinity climatology (WOA 2009) allows us to determine the barotropic circulation of oceanic basins under geostrophic and mass conservation assumptions. In contrast with other direct methods such as Mellor et al. (1982) and Bogden et al. (1993), the vorticity equation is not used and the present approach keeps Rossby number accuracy. Simple vertical integration of the absolute geostrophic currents provides a first guess for the barotropic transports that fail to conserve mass or satisfy boundary conditions on continents. To filter out this divergence, we obtain a streamfunction by inverting the barotropic vorticity given Dirichlet boundary conditions on solid and open boundaries. The barotropic streamfunction provides a global picture of Eulerian time-mean barotropic transports of all major current systems and their inertial recirculations. The transports are usually in the range of previously reported local determinations, with only the ACC being significantly more energetic with its 175-Sv transport. New estimates are also provided for the anticyclonic inertial recirculation in the North Atlantic (72 Sv) and North Pacific (82 Sv). The small-scale Zapiola Gyre in the South Atlantic with its 124-Sv transport becomes a singularity on a barotropic transport map. In the interior, the Sverdrup streamfunction recovers the overall shape of the observed gyres, and the line of zero wind stress curl follows quite well the boundaries of the subtropical and subpolar gyres in the North Atlantic and North Pacific. However, it is not quantitatively correct and falls short of the observations 
in the interior by roughly a factor of 2, except for certain latitudes in the east Pacific or south Indian Oceans. This means implicitly that the averaged bottom torque in (23) has the same sign as the wind stress curl to enhance the subtropical gyres. If the atmosphere is an example, bottom turbulent stresses and eddy and internal gravity wave form drag may contribute as well. Alternatively, one may choose to attribute the discrepancy with the Sverdrup transport to two possible causes:

(i) The lack of convergence of the time-mean flow. Based on the geopotential errors at $1000 \mathrm{db}$ by $\mathrm{OCV}$, we believe that the barotropic transport random errors do not exceed $\pm 5 \mathrm{~Sv}$ over much of the subtropical gyres and are therefore unable to explain the large difference found above. At any rate the errors of this time-mean barotropic circulation will decrease as (number of floats) ${ }^{-1 / 2}$ and many Argo float displacements have yet to be validated and integrated in the ANDRO database.

(ii) Uncertainties in the wind stress curl. But this is more difficult to assess; there are places (in the subpolar gyres) where the Sverdrup relation is nearly satisfied. In the subtropical gyres, it would require doubling the drag coefficient of the wind stress, but current uncertainties are much lower than that [see the recent discussion by Risien and Chelton (2008)]. Therefore, the implicit importance given here to bottom torques supports the reconstruction of Mellor et al. (1982) and primitive equation model simulations of Holland (1972), Greatbatch et al. (1991), and Hughes and de Cuevas (2001), who observed that bottom torques increased the strength of the circulation when the fluid was stratified. Note that Cane et al. (1998) argued for the opposite, namely, that density compensation zeroed the bottom flow supporting Godfrey's (1989) flat-bottom World Ocean calculation. However, the argument is a direct consequence of Gill's catastrophe (the final stage of the linear spinup of a wind-driven flow with the circulation concentrated in the upper layer) studied in the topographic case by Anderson and Killworth (1977) and leaves aside the deep thermohaline circulation forced by surface buoyancy fluxes.

Finally, we have compared the present solution with the barotropic streamfunction from Wunsch (2011), which results from the time average of a 16-yr duration time-varying ocean circulation estimate with the ECCO consortium (Wunsch et al. 2009) with constraints similar to Mazloff et al. (2010) (they do not include the Argo float database used here). The present solution based on hydrography and direct current measurements at depth is stronger with the rms of the difference between the two circulations equal to $13.4 \mathrm{~Sv}$. In turn, Wunsch's weaker circulation is closer to the Sverdrup predictions in the subtropical gyres. The difference between Wunsch's streamfunction and the present one is largest in energetic areas such as the inertial recirculations in the North Atlantic and North Pacific Oceans ( $~ 50-\mathrm{Sv}$ difference). The jet character of the Agulhas Current is also stronger here. The Zapiola Gyre marks the strongest difference since it is absent from Wunsch's solution. At several places in the ACC our solutions are more energetic (Ross Gyre, downstream of Drake Passage, and south of Kerguelen Island). The present conclusion is that the reference of the dynamic method to the Argoderived, 1000-db, observed circulation brings a new, more energetic picture of the barotropic circulation. To find out if the longer time averaging in Wunsch's (2011) solution may explain some of the differences between the two circulations, it is pressing to pursue the development of this high-quality Argo float displacement database. Such efforts will also allow in turn the important determination of heat and freshwater transports and overturning streamfunctions. Given that the largescale barotropic state is also the favored state of turbulent energy cascades, a well-observed barotropic state can become a useful benchmark for the improvement of eddy-resolving OGCMs.

Acknowledgments. We thank C. Wunsch for allowing comparison with his 2011 barotropic streamfunction and his comments on a first draft of this article. Comments by T. Huck, Y. H. Park, P. Penven, and R. Schopp and the careful reading and pertinent suggestions of the two reviewers are gratefully acknowledged.

\section{REFERENCES}

Anderson, D. L. T., and P. D. Killworth, 1977: Spin-up of a stratified ocean with topography. Deep-Sea Res., 24, 709-732, doi:10.1016/0146-6291(77)90495-7.

Antonov, J. I., and Coauthors, 2010: Salinity. Vol. 2, World Ocean Atlas 2009, NOAA Atlas NESDIS 69, 184 pp.

Arbic, B. K., and Coauthors, 2009: Estimates of bottom flows and bottom boundary layer dissipation of the oceanic general circulation from global high-resolution models. J. Geophys. Res., 114, C02024, doi:10.1029/2008JC005072.

Barrett, J. R., Jr., 1965: Subsurface currents off Cape Hatteras. Deep-Sea Res. Oceanogr. Abstr., 12, 173-184, doi:10.1016/ 0011-7471(65)90023-9.

_ , and W. J. Schmitz, 1971: Transport float measurements and hydrographic station data from three sections across the Gulf Stream near $67^{\circ} \mathrm{W}$. Woods Hole Oceanographic Institution Tech. Rep. 71-66.

Bell, T. H., 1975: Statistical features of sea-floor topography. Deep-Sea Res. Oceanogr. Abstr., 22, 883-892, doi:10.1016/ 0011-7471(75)90090-X. 
Bogden, P. S., R. E. Davis, and R. Salmon, 1993: The North Atlantic circulation: Combining simplified dynamics with hydrographic data. J. Mar. Res., 51, 1-52, doi:10.1357/ 0022240933223855.

Bower, A. S., and Coauthors, 2002: Directly-measured mid-depth circulation in the northeastern North Atlantic Ocean. Nature, 419, 603-607, doi:10.1038/nature01078.

Bryan, K., 1962: Measurements of meridional heat transports by ocean currents. J. Geophys. Res., 67, 3403-3414, doi:10.1029/ JZ067i009p03403.

— , and M. D. Cox, 1972: The circulation of the World Ocean: A numerical study. Part I, A homogeneous model. J. Phys. Oceanogr., 2, 319-335, doi:10.1175/1520-0485(1972)002<0319: TCOTWO $>2.0 . \mathrm{CO} ; 2$

Bryden, H. L., L. M. Beal, and L. M. Duncan, 2005: Structure and transport of the Agulhas current and its temporal variability J. Oceanogr., 61, 479-492, doi:10.1007/s10872-005-0057-8.

Cane, M. A., V. M. Kamenkovich, and A. Krupitsky, 1998: On the utility and disutility of JEBAR. J. Phys. Oceanogr., 28, 519-526, doi:10.1175/1520-0485(1998)028<0519:OTUADO > 2.0.CO;2.

Casal, T. G. D., L. M. Beal, R. Lumkin, and W. E. Johns, 2009: Structure and downstream evolution of the Agulhas Current system during a quasi-synoptic survey in February-March 2003. J. Geophys. Res., 114, C03001, doi:10.1029/2008JC004954.

Charney, J., 1955: The use of primitive equations of motion in numerical prediction. Tellus, 7A, 22-26, doi:10.1111/ j.2153-3490.1955.tb01138.x.

Clarke, R. A., H. W. Hill, R. F. Reiniger, and B. A. Warren, 1980: Current system south and east of the Grand Banks of Newfoundland. J. Phys. Oceanogr., 10, 25-65, doi:10.1175/ 1520-0485(1980)010<0025:CSSAEO $>2.0 . \mathrm{CO} ; 2$

Cunningham, S. A., S. G Alderson, B. A. King, and M. A. Brandon, 2003: Transport and variability of the Antarctic Circumpolar Current in Drake Passage. J. Geophys. Res., 108, 8084 doi:10.10292001JC001147.

Davis, R. E., 2005: Intermediate-depth circulation of the Indian and south Pacific Oceans measured by autonomous floats. J. Phys. Oceanogr., 35, 683-707, doi:10.1175/JPO2702.1.

De Miranda, A. P., B. Barnier, and W. K. Dewar, 1999: One the dynamics of the Zapiola anticyclone. J. Geophys. Res., 104, 21 137-21 149, doi:10.1029/1999JC900042.

Dewar, W. K., 1998: Topography and barotropic transport control by bottom friction. J. Mar. Res., 56, 295-328, doi:10.1357/ 002224098321822320

Donohue, K., 2015: A four year time series of Antarctic circumpolar current transport through Drake Passage from moored observations. Extended Abstracts, 26th IUGG General Assembly, Prague, Czech Republic, International Union of Geodesy and Geophysics, IUGG-5412.

Ezer, T., and G. L. Mellor, 1994: Diagnostic and prognostic calculations of the North Atlantic circulation and sea level using a sigma coordinate ocean model. J. Geophys. Res., 99, 14159 14 172, doi:10.1029/94JC00859.

Fofonoff, N. P., 1962: The sea, ideas and observations. Dynamics of Ocean Currents, Vol. 1, Pergamon Press, 323-396.

Fuglister, F. C., 1963: Gulf Stream '60. Prog. Oceanogr., 1, 265-373, doi:10.1016/0079-6611(63)90007-7.

Ganachaud, A., and C. Wunsch, 2000: Improved estimates of global ocean circulation, heat transport and mixing from hydrographic data. Nature, 408, 453-457, doi:10.1038/ 35044048

Gille, S., 1997: Why potential vorticity is not conserved along mean streamlines in a numerical Southern Ocean. J. Phys.
Oceanogr., 27, 1286-1299, doi:10.1175/1520-0485(1997)027<1286: WPVINC $>2.0 . \mathrm{CO} ; 2$.

2003: Float observations of the Southern Ocean. Part I: Estimating mean fields, bottom velocities, and topographic steering. J. Phys. Oceanogr., 33, 1167-1181, doi:10.1175/ 1520-0485(2003)033<1167:FOOTSO > 2.0.CO;2.

Godfrey, J. S., 1989: A Sverdrup model of the depth integrated flow for the World Ocean allowing for island circulations. Geophys. Astrophys. Fluid Dyn., 45, 89-112, doi:10.1080/ 03091928908208894

Gray, A. R., and S. C. Riser, 2014: A global analysis of Sverdrup balance using absolute geostrophic velocities from Argo. J. Phys. Oceanogr., 44, 1213-1229, doi:10.1175/JPO-D-12-0206.1.

Greatbatch, R. J., A. F. Fanning, and A. D. Goulding, 1991: A diagnosis of interpentadal circulation changes in the North Atlantic. J. Geophys. Res., 96, 22 009-22 023, doi:10.1029/ 91JC02423.

Halkin, D., and T. Rossby, 1985: The structure and transport of the Gulf Stream at $73^{\circ} \mathrm{W}$. J. Phys. Oceanogr., 15, 1439-1452, doi:10.1175/1520-0485(1985)015<1439:TSATOT>2.0.CO;2.

Hall, M. M., and H. L. Bryden, 1982: Direct estimates and mechanisms of ocean heat transport. Deep-Sea Res., 29, 339-360, doi:10.1016/0198-0149(82)90099-1.

Harlander, U., H. Ridderinkhof, M. W. Schouten, and W. P. M. de Ruijter, 2009: Long-term observations of transport, eddies, and Rossby waves in the Mozambique Channel. J. Geophys. Res., 114, C02003, doi:10.1029/2008JC004846.

Hautala, S. L., D. H. Roemmich, and W. J. Schmitz Jr., 1994: Is the North Pacific in Sverdrup balance along $24^{\circ} \mathrm{N}$ ? J. Geophys. Res., 99, 16041-16 052, doi:10.1029/94JC01084.

Hogg, N. G., 1992: On the transport of the Gulf Stream between Cape Hatteras and the Grand Banks. Deep-Sea Res., 39, 12311246, doi:10.1016/0198-0149(92)90066-3.

Holland, W. R., 1972: Baroclinic and topographic influences on the transport in western boundary currents. Geophys. Fluid Dyn., 4, 187-210, doi:10.1080/03091927208236095.

, 1978: The role of mesoscale eddies in the general circulation of the ocean-Numerical experiments using a wind-driven quasi-geostrophic model. J. Phys. Oceanogr., 8, 363-392, doi:10.1175/1520-0485(1978)008<0363:TROMEI >2.0.CO;2.

_ _ and A. D. Hirschman, 1972: A numerical calculation of the circulation of the North Atlantic Ocean. J. Phys. Oceanogr., 2, 336-354, doi:10.1175/1520-0485(1972)002<0336: ANCOTC $>2.0 . \mathrm{CO} ; 2$

Huck, T., A. Colin de Verdière, P. Estrade, and R. Schopp, 2008: Low-frequency variations of the large scale ocean circulation and heat transport in the North Atlantic from 1955-1998 in situ temperature and salinity data. Geophys. Res. Lett., 35 , L23613, doi:10.1029/2008GL035635.

Hughes, C. W., and B. A. de Cuevas, 2001: Why western boundary currents in realistic oceans are inviscid: A link between form stress and bottom pressure torques. J. Phys. Oceanogr., 31, 2871-2885, doi:10.1175/1520-0485(2001)031<2871:WWBCIR>2.0.CO;2.

Imawaki, S., H. Ushida, H. Ichikawa, M. Fukasawa, and S. Umatani, 2001: Satellite altimeter monitoring the Kuroshio transport south of Japan. Geophys. Res. Lett., 28, 17-20, doi:10.1029/2000GL011796.

Johns, W. E., T. J. Shay, J. M. Bane, and D. R. Watts, 1995: Gulf Stream structure, transport, and recirculation near $68^{\circ} \mathrm{W}$. J. Geophys. Res., 100, 817-838, doi:10.1029/94JC02497.

Johnson, G. C., and H. L. Bryden, 1989: On the size of the Antarctic Circumpolar Current. Deep-Sea Res., 36, 39-53, doi:10.1016/ 0198-0149(89)90017-4. 
Kamenkovitch, V. M, 1962: On the theory of the Antarctic Circumpolar Current. Tr. Inst. Okeanol. Akad. Nauk SSSR, 56, 241.

Katsumata, K., and H. Yoshinari, 2010: Uncertainties in global mapping of Argo drift data at the parking level. J. Oceanogr., 66, 553-569, doi:10.1007/s10872-010-0046-4.

Knauss, J. A., 1969: A note on the transport of the Gulf Stream. Deep-Sea Res., 16, 117-123.

Koenig, Z., C. Provost, R. Ferrari, N. Sennéchael, and M.-H. Rio, 2014: Volume transport of the Antarctic Circumpolar Current: Production and validation of a 20 year long time series obtained from in situ and satellite observations. J. Geophys. Res. Oceans, 119, 5407-5433, doi:10.1002/ 2014JC009966.

Lamas, L., Á. Peliz, I. Ambar, A. B. Aguiar, N. Maximenko, and A. Teles-Machado, 2010: Evidence of time-mean cyclonic cell southwest of Iberian Peninsula: The Mediterranean outflow-driven $\beta$-plume? Geophys. Res. Lett., 37, L12606, doi:10.1029/2010GL043339.

Large, W. G., and S. G. Yeager, 2004: Diurnal to decadal global forcing for ocean and sea-ice models: The data sets and flux climatologies. NCAR Tech. Rep. TN-460+STR, 122 pp.

Lavender, K. L., R. E. Davis, and W. B. Owens, 2000: Mid-depth recirculation observed in the interior Labrador and Irminger Seas by direct velocity measurements. Nature, 407, 66-69, doi:10.1038/35024048.

Leaman, K. D., E. Johns, and H. T. Rossby, 1989: The average distribution of volume transport and potential vorticity with temperature at three sections across the Gulf Stream. J. Phys. Oceanogr., 19, 36-51, doi:10.1175/1520-0485(1989)019<0036: TADOVT $>2.0 . \mathrm{CO} ; 2$.

Leetmaa, A., P. Niiler, and H. Stommel, 1977: Does the Sverdrup relation account for the Mid-Atlantic circulation? J. Mar. Res., 35, 1-10.

Locarnini, R. A., A. V. Mishonov, J. I. Antonov, T. P. Boyer, H. E. Garcia, O. K. Baranova, M. M. Zweng, and D. R. Johnson, 2010. Temperature. Vol. 1, World Ocean Atlas 2009, NOAA Atlas NESDIS 68, 184 pp.

Luyten, J., H. Stommel, and C. Wunsch, 1985: A diagnostic study of the northern Atlantic subpolar gyre.J. Phys. Oceanogr., 15, 1344-1348, doi:10.1175/1520-0485(1985)015<1344:ADSOTN>2.0.CO;2.

MacDonald, A. M., and C. Wunsch, 1996: An estimate of global ocean circulation and heat fluxes. Nature, 382, 436-439, doi:10.1038/382436a0.

Mann, C. R., 1967: The termination of the Gulf Stream and the beginning of the North Atlantic Current. Deep-Sea Res. Oceanogr. Abstr., 14, 337-359, doi:10.1016/0011-7471(67)90077-0.

Maximenko, N., P. Niiler, M.-H. Rio, O. Melnichenko, L. Centurioni, D. Chambers, V. Zlotnicki, and B. Galperin, 2009: Mean dynamic topography of the ocean derived from satellite and drifting buoy data using three different techniques. J. Atmos. Oceanic Technol., 26, 1910-1919, doi:10.1175/ 2009JTECHO672.1.

Mazloff, M. R., P. Heimbach, and C. Wunsch, 2010: An eddypermitting Southern Ocean estimate. J. Phys. Oceanogr., 40, 880-899, doi:10.1175/2009JPO4236.1.

Mellor, G. L., C. R. Mechoso, and E. Keto, 1982: A diagnostic calculation of the general circulation of the Atlantic Ocean. DeepSea Res., 29, 1171-1192, doi:10.1016/0198-0149(82)90088-7.

Mercier, H., M. Ollitrault, and P. Y. Le Traon, 1993: An inverse model of the North Atlantic general circulation using Lagrangian float data. J. Phys. Oceanogr., 23, 689-715, doi:10.1175/1520-0485(1993)023<0689:AIMOTN>2.0.CO;2.
Munk, W. H., 1950: On the wind-driven ocean circulation. J. Meteor., 7, 80-93, doi:10.1175/1520-0469(1950)007<0080: OTWDOC $>2.0 . \mathrm{CO} ; 2$.

— , and E. Palmen, 1951: Note on dynamics of the Antarctic Circumpolar Current. Tellus, 3A, 53-55, doi:10.1111/ j.2153-3490.1951.tb00776.x.

Niiler, P. N., N. A. Maximenko, and J. C. McWilliams, 2003: Dynamically balanced absolute sea level of the global ocean derived from near-surface velocity observations. Geophys. Res. Lett., 30, 2164, doi:10.1029/2003GL018628.

Nowlin, W. D., Jr., and J. M. Klinck, 1986: The physics of the Antarctic circumpolar current. Rev. Geophys., 24, 469-491, doi:10.1029/RG024i003p00469.

Olbers, D. J., M. Wentzel, and J. Willebrand, 1985: The inference of North Atlantic circulation patterns from climatological hydrographic data. Rev. Geophys., 23, 313-356, doi:10.1029/ RG023i004p00313.

_ D. Borovski, C. Volker, and J. O. Wolff, 2004: The dynamical balance, transport, and circulation of the Antarctic circumpolar current. Antarct. Sci., 16, 439-470, doi:10.1017/ S0954102004002251.

Ollitrault, M., and J. P. Rannou, 2013: ANDRO: An Argo-based deep displacement dataset. J. Atmos. Oceanic Technol., 30, 759-788, doi:10.1175/JTECH-D-12-00073.1.

_ , and A. Colin de Verdière, 2014: The ocean general circulation near 1000-m depth. J. Phys. Oceanogr., 44, 384-409, doi:10.1175/JPO-D-13-030.1.

Paillet, J., and H. Mercier, 1997: An inverse model of the eastern North Atlantic general circulation and thermocline ventilation. DeepSea Res., 44, 1293-1328, doi:10.1016/S0967-0637(97)00019-8.

Park, Y. H., and J. M. Guernier, 2001: A simple method for diagnosing the bottom current field of the World's Oceans. J. Phys. Oceanogr., 31, 972-990, doi:10.1175/1520-0485(2001)031<0972: ASMFDT $>2.0 . \mathrm{CO} ; 2$.

- F. Vivier, F. Roquet, and E. Kestenare, 2009: Direct observations of the ACC transport across the Kerguelen Plateau. Geophys. Res. Lett., 36, L18603, doi:10.1029/2009GL039617.

Pedlosky, J., 1996: Ocean Circulation Theory. Springer, 453 pp.

Provost, C., and R. Salmon, 1986: A variational method for inverting hydrographic data. J. Mar. Res., 44, 1-34, doi:10.1357/ 002224086788460175.

Qiu, B., and T. M. Joyce, 1992: Interannual variability in the mid and low latitude western North Pacific. J. Phys. Oceanogr., 22, 10621079, doi:10.1175/1520-0485(1992)022<1062:IVITMA > 2.0.CO;2

Reid, J. L., 1994: On the total geostrophic circulation of the North Atlantic Ocean: Flow patterns, tracers, and transports. Prog. Oceanogr., 33, 1-92, doi:10.1016/0079-6611(94)90014-0.

_ 1997: On the total geostrophic circulation of the Pacific Ocean: Flow patterns, tracers, and transports. Prog. Oceanogr., 39, 263-352, doi:10.1016/S0079-6611(97)00012-8.

Rhines, P. B., 1977: The dynamics of unsteady currents. Marine Modeling, E. D. Goldberg et al., Eds., The Sea-Ideas and Observations on Progress in the Study of the Seas, Vol. 6, John Wiley and Sons, 189-318.

Richardson, P. L., 1985: Average velocity and transport of the Gulf Stream near $55^{\circ}$ W. J. Mar. Res., 43, 83-111, doi:10.1357/ 002224085788437343.

Ridderinkhof, H., and W. P. M. de Ruijter, 2003: Moored current observations in the Mozambique Channel. Deep-Sea Res. II, 50, 1933-1955, doi:10.1016/S0967-0645(03)00041-9.

Rio, M. H., S. Mulet, and N. Picot, 2014: Beyond GOCE for the ocean circulation estimate: Synergetic use of altimetry, gravimetry, and in situ data provides new insight into geostrophic 
and Ekman currents. Geophys. Res. Lett., 41, 8918-8925, doi:10.1002/2014GL061773.

Risien, C. M., and D. B. Chelton, 2008: A global climatology of surface wind and wind stress fields from eight years of QuikSCAT scatterometer data. J. Phys. Oceanogr., 38, 23792413, doi:10.1175/2008JPO3881.1.

Roemmich, D., and T. McCallister, 1989: Large scale circulation of the North Pacific Ocean. Prog. Oceanogr., 22, 171-204, doi:10.1016/0079-6611(89)90005-0.

Salmon, R., 1980: Baroclinic instability and geostrophic turbulence. Geophys. Astrophys. Fluid Dyn., 15, 167-211, doi:10.1080/03091928008241178.

_ 1994: Generalized two-layer models of ocean circulation. J. Mar. Res., 52, 865-908, doi:10.1357/0022240943076939.

Sarkisyan, A. S., and F. F. Ivanov, 1971: Joint effect of baroclinicity and bottom relief as an important factor in the dynamics of the sea currents. Izv. Akad. Sci. USSR Atmos. Oceanic Sci., 1, 173-188.

_ , and V. P. Keonjiyan, 1975: Review of numerical ocean circulation models using the observed density field. Numerical Models of Ocean Circulation, National Academy of Science, 76-93.

Sarmiento, J. L., and K. Bryan, 1982: An ocean transport model for the North Atlantic. J. Geophys. Res., 87, 394-408, doi:10.1029/ JC087iC01p00394.

Saunders, P. M., and B. A. King, 1995: Bottom currents derived from a shipborne ADCP on WOCE cruise A11 in the South Atlantic. J. Phys. Oceanogr., 25, 329-347, doi:10.1175/ 1520-0485(1995)025<0329:BCDFAS $>2.0$. CO; 2 .

Schmitz, W. J., J. D. Thompson, and J. R. Luyten, 1992: The Sverdrup circulation for the Atlantic along $24^{\circ} \mathrm{N}$. J. Geophys. Res., 97, 7251-7256, doi:10.1029/92JC00417.

Sloyan, B. M., and S. R. Rintoul, 2001: Circulation, renewal, and modification of Antarctic Mode Water and Intermediate Water. J. Phys. Oceanogr., 31, 1005-1030, doi:10.1175/ 1520-0485(2001)031<1005:CRAMOA>2.0.CO;2.

Smith, R., 1978: A measurement of mountain drag. J. Atmos. Sci., 35, 1644-1654, doi:10.1175/1520-0469(1978)035<1644: AMOMD $>2.0 . \mathrm{CO} ; 2$

Sprintall, J., S. E. Wijffels, R. Molcard, I. Jaya, 2009: Direct estimates of the Indonesian Throughflow entering the Indian ocean: 2004 2006. J. Geophys. Res., 114, C07001, doi:10.1029/2008JC005257.

Stevens, D. P., and V. O. Ivchenko, 1997: The zonal momentum balance in an eddy-resolving general-circulation model of the Southern Ocean. Quart. J. Roy. Meteor. Soc., 123, 929-951, doi:10.1002/qj.49712354008.

Stommel, H., and A. B. Arons, 1960a: On the abyssal circulation of the World Ocean-I. Stationary planetary flow patterns on a sphere. Deep-Sea Res., 6, 140-154, doi:10.1016/0146-6313(59)90065-6.

_ and $1960 \mathrm{~b}$ : On the abyssal circulation of the World Ocean-II. An idealized model of the circulation pattern and amplitude in oceanic basins. Deep-Sea Res., 6, 217-223, doi:10.1016/0146-6313(59)90075-9.
- and F. Schott, 1977: The beta spiral and the determination of the absolute velocity field from hydrographic station data. Deep-Sea Res., 24, 325-329, doi:10.1016/0146-6291(77)93000-4.

Sverdrup, H. U., 1947: Wind driven currents in a baroclinic ocean; with applications to the equatorial currents of the eastern Pacific. Proc. Natl. Acad. Sci. USA, 33, 318-326, doi:10.1073/ pnas.33.11.318.

Talley, L. D., G. L. Pickard, W. J. Emery, and J. H. Swift, 2011: Descriptive Physical Oceanography: An Introduction. 6th ed. Elsevier, 555 pp.

Warren, B. A., and G. H. Volkmann, 1968: Measurements of volume transport of the Gulf Stream south of New England. J. Mar. Res., 26, 110-126.

Welander, P., 1959: On the vertically integrated mass transport in the ocean. The Atmosphere and the Sea in Motion, B. Bolin, Ed., Rockefeller Institute Press, 95-101.

Wijffels, S., R. W. Schmitt, H. L. Bryden, and A. Stigebrandt, 1992: Transport of freshwater by the oceans. J. Phys. Oceanogr., 22, 155-162, doi:10.1175/1520-0485(1992)022<0155: TOFBTO $>2.0 . \mathrm{CO} ; 2$

Willis, J. K., and L.-L. Fu, 2008: Combining altimeter and subsurface float data to estimate the time-averaged circulation in the upper ocean. J. Geophys. Res., 113, C12017, doi:10.1029/ 2007JC004690.

Woodgate, R. A., T. J. Weingartner, and R. Lindsay, 2012: Observed increases in Bering Strait oceanic fluxes from the Pacific to the Arctic from 2001 to 2011 and their impacts on the Arctic Ocean water column. Geophys. Res. Lett., 39, L24603, doi:10.1029/2012GL054092.

Worthington, L. V., 1976: On the North Atlantic circulation. Oceanographic Studies, John Hopkins University, 110 pp.

Wunsch, C., 1978: The North Atlantic circulation west of $50^{\circ} \mathrm{W}$ determined by inverse methods. Rev. Geophys. Space Phys., 16, 583-620, doi:10.1029/RG016i004p00583. 1996: The Ocean Circulation Inverse Problem. Cambridge University Press, $442 \mathrm{pp}$

- 2011: The decadal mean ocean circulation and Sverdrup balance. J. Mar. Res., 69, 417-434, doi:10.1357/ 002224011798765303

, and B. Grant, 1982: Towards the general circulation of the North Atlantic Ocean. Prog. Oceanogr., 11, 1-59, doi:10.1016/ 0079-6611(82)90010-6.

, and D. Roemmich, 1985: Is the North Atlantic in Sverdrup balance? J. Phys. Oceanogr., 15, 1876-1880, doi:10.1175/ 1520-0485(1985)015<1876:ITNAIS $>2.0$. CO; 2 .

—-, and P. Heimbach, 2007: Practical global oceanic state estimation. Physica D, 230, 197-208, doi:10.1016/ j.physd.2006.09.040.

,,- R. M. Ponte, and I. Fukumori, 2009: The global general circulation of the ocean estimated by the ECCO-consortium. Oceanography, 22, 88-103, doi:10.5670/oceanog.2009.41. 